Portland State University

PDXScholar

Summer 8-8-2019

\title{
"To Call or Not to Call?" The Impact of Supervisor Training on Call Center Employee Attitudes and Well- Being
}

Whitney Elan Schneider Vogel

Portland State University

Follow this and additional works at: https://pdxscholar.library.pdx.edu/open_access_etds

Part of the Psychology Commons

Let us know how access to this document benefits you.

\section{Recommended Citation}

Vogel, Whitney Elan Schneider, "'To Call or Not to Call?" The Impact of Supervisor Training on Call Center Employee Attitudes and Well-Being" (2019). Dissertations and Theses. Paper 5242.

https://doi.org/10.15760/etd.7115

This Thesis is brought to you for free and open access. It has been accepted for inclusion in Dissertations and Theses by an authorized administrator of PDXScholar. Please contact us if we can make this document more accessible: pdxscholar@pdx.edu. 
"To Call or Not to Call?"

The Impact of Supervisor Training on Call Center Employee

Attitudes and Well-Being

by

Whitney Elan Schneider Vogel

A thesis submitted in partial fulfillment of the requirements for the degree of

Master of Science

in

Psychology

Thesis Committee:

Jennifer Dimoff, Chair

Leslie Hammer

Jason Newsom

Portland State University

2019 
(C) 2019 Whitney Elan Schneider Vogel 


\begin{abstract}
Call center customer service occupations represent a growing proportion of the U.S. economy in the digital age. These roles are characterized by low control, high levels of emotional labor, and burnout. Turnover rates in call centers are often twice as high as in other industries. To combat these challenges, I delivered a supervisor-focused mental health training intervention targeted at improving supervisor supportive behaviors and employee outcomes. The indirect effect of supervisor training on employee outcomes related to perceived supervisor support, problem-focused coping, burnout, turnover intentions, and withdrawal behaviors were evaluated. A waitlist control design $(N=74)$ was used to assess the effectiveness of the training up to six weeks after the intervention. Additionally, a weekly diary study evaluated the process of behavior and attitude change for employees. Results indicated that the intervention did not impact the hypothesized employee outcomes up to six weeks following training. Implications, limitations, and future directions are discussed.
\end{abstract}




\section{Table of Contents}

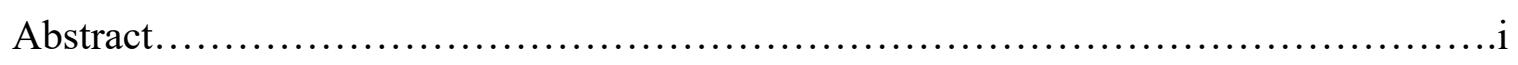

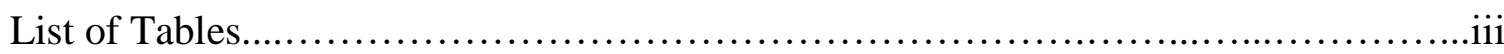

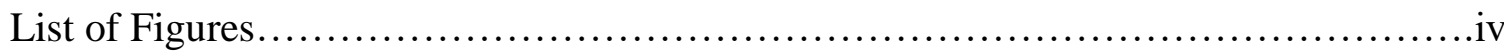

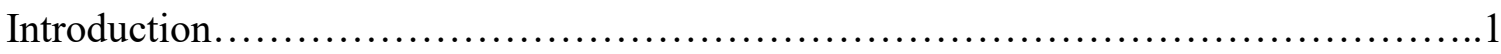

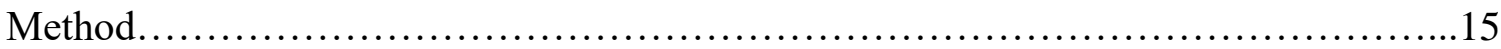

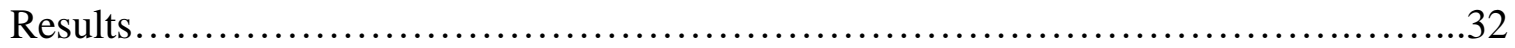

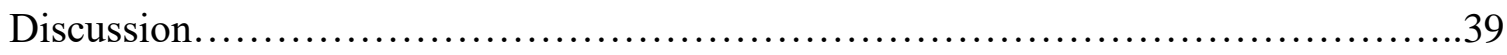

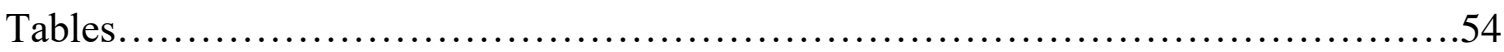

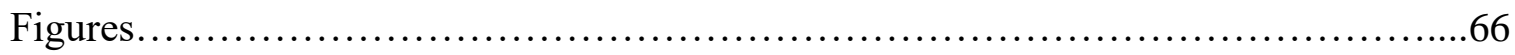

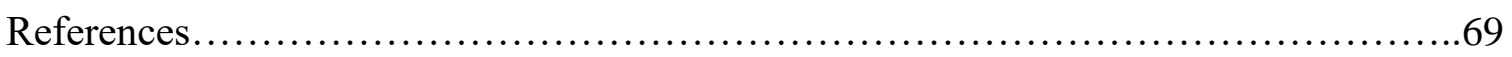

Appendix A: Assessment measures.................................................... 86

Appendix B: Weekly diary survey measures....................................... 90 


\section{List of Tables}

Table 1: Employee demographics...........................................54

Table 2: Correlations between the employee variables (intervention group)...........55-56

Table 3: Correlations between the employee variables (control group)..............57-58

Table 4: Univariate effects for repeated measures MANOVA.......................59

Table 5: Research Question 1: Growth Curve Analyses ..........................60

Table 6: Research Question 2: Growth Curve Analyses ..........................61-62

Table 7: Research Question 3: Growth Curve Analyses .............................63

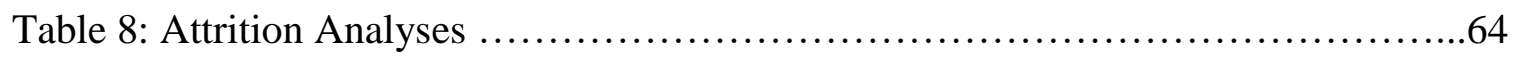

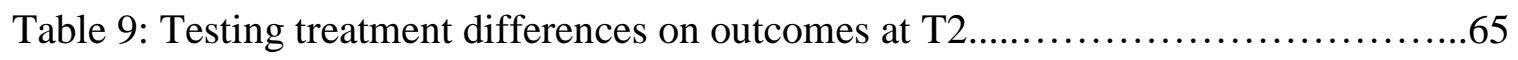




\section{List of Figures}

Figure 1: Hypothesized employee behaviors and outcomes.........................66

Figure 2: Hypothesized employee growth curve interactions $\ldots \ldots \ldots \ldots \ldots \ldots \ldots \ldots \ldots . \ldots 6$

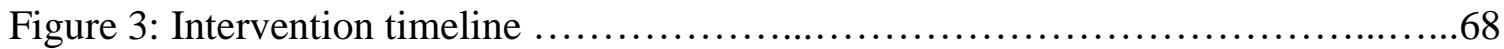




\section{Introduction}

There were more than 2.7 million customer service representative jobs in the United States in 2016. According to the U.S. Department of Labor (2018), by 2026, that number is expected to grow by $5 \%$. Customer service representatives interact with a company's customers to handle complaints, deliver customer care, and process orders. Often, the only interface a customer has with a company is through customer service representatives. Many customer service positions do not require post-secondary degrees, and with a median wage of $\$ 15.53 /$ hour (U.S. Department of Labor, 2018), companies are entrusting front-line employees with interactions that affect customers' perceptions of quality (Bowen, Siehl, \& Schneider, 1989). As the digital age progresses, more customer service jobs are moving from in-person customer interactions to over-the-phone or online interactions via call centers or remote locations. Annual turnover in call centers was $29 \%$ in 2016 (ContactBabel, 2016), roughly twice that of many industries. Typically considered to be emotionally exhaustive, highly monitored, and minimally engaging, most front-line call center positions in North America elicit significantly higher rates of turnover and absenteeism than almost any other department or industry (Dulewicz \& Higgs, 2000; Hochschild, 1983).

Often, it is logistically impractical and financially infeasible for many organizations to redesign call center positions in a way that completely eliminates certain job characteristics that make the job so exhausting to employees. Characteristics such as call volume, expectations surrounding call length, and the required use of specific "branded" language are all critical to customer experience and organizational success 
(Batt \& Moynihan, 2002). Rather than change the requirements of the job itself, many call center organizations have sought to redesign the workplace and/or the "culture" of the organization to reduce turnover and increase employee satisfaction (Attridge, 2009; Cooper \& Cartwright, 1994; Wright, Szeto, \& Geroy, 2007). The majority of call center research in recent years has focused on how call centers can employ organizational strategies related to recruitment, selection, health promotion, and engagement in order to attract and retain employees (Holman \& Axtell, 2016; Reb, Narayanan, Chaturvedi, \& Ekkirala, 2017). These foci emphasize organizational strategies but neglect the role of supervisors, who frequently interact with call center employees, to monitor performance. Little attention has been paid to understanding the unique leadership and management techniques that might be required to help retain a healthy and productive call center workforce. The present study extends current research in this area.

Mental health and well-being are of particular interest given the relationship between burnout and mental health issues, such as anxiety and depression (Ahola et al., 2005). Recent research has demonstrated that supervisor-focused mental health training can lead to changes in supervisor behavior that impacts employee willingness to seek out resources and perceive supervisors as sources of social support (Dimoff \& Kelloway, 2019). However, this supervisor mental health intervention research did not evaluate objective employee outcomes, such as turnover, nor did this research evaluate the processes by which the leader training precipitated change at the employee-level (Dimoff \& Kelloway, 2019; Dimoff, Kelloway, \& Burnstein, 2016; Kitchener \& Jorm, 2008). 
Therefore, the present study builds upon this research by evaluating the impact of supervisor mental health training on employee attitudes and behaviors. To do so, I use the lens of the job demands-resources model (JD-R; Demerouti, Bakker, Nachreiner, \& Schaufeli, 2001) to evaluate the extent to which a supervisor-focused mental health training intervention can act as an indirect resource designed to buffer the job demands faced by call center employees. Specifically, I evaluate the impact of a supervisor training on employee a) perceptions of supervisor support, b) adaptive coping behaviors, c) burnout, d) withdrawal behaviors, and e) turnover intentions.

\section{Understanding the Call Center Turnover Process}

One of the explanations surrounding the high rate of turnover among call center employees is related to burnout (Kraemer \& Gouthier, 2014). Burnout is the result of chronic strain which leads to a state of feeling physically and emotionally exhausted, detached, cynical, and lacking feelings of personal accomplishment (Maslach \& Jackson, 1986). Companies looking to reduce costs associated with high turnover must address the personal and environmental factors that contribute to burnout. Burnout has consistently been linked to turnover, the intention to quit, poor performance, and negative attitudes (Brotheridge \& Grandey, 2002).

To understand the role of burnout in call center occupations, I turn to the job demands-resources model (JD-R; Demerouti, Bakker, Nachreiner, \& Schaufeli, 2001), which posits that every occupation, regardless of industry and specific job, consists of job demands that are stressors and job resources that are needed to overcome job demands. 
Examples of job demands include work overload, role ambiguity, and both emotional and physical requirements. Over time, job demands can cause strain. The strain caused by job demands leads to negative health outcomes, such as burnout and other deteriorations in mental health (Parker, Morgeson, \& Johns, 2017). Scheduling restrictions, quality assurance standards, and lack of job control are just a few of the job demands common in call center occupations.

Job resources include autonomy, emotional support, and feedback. Resources have the power to buffer against the depleting effects of job demands (Bakker \& Demerouti, 2007) and produce high levels of performance and positive well-being through motivation (Parker et al., 2017). Resources can be internal or external to the individual, and can be provided by the company (Brotheridge \& Grandey, 2002). When the resources available to an employee are not sufficient to meet the demands of the job, an imbalance occurs. Resource depletion is a source of strain because it threatens the innate desire to build, protect, and retain resources (Hobfoll, 1989). Resources must be sufficiently maintained and replenished in order to address the environmental demands of the job (Bates et al., 2010). When an imbalance between demands and resources exists, such that job demands outweigh resources available, burnout can ensue (Demerouti et al., 2001). The emotional exhaustion and cynicism associated with burnout can lead to mental health impairment (Schaufeli \& Bakker, 2004) and disengagement, including withdrawal behaviors (e.g., absenteeism) and intentions to leave the organization (Demerouti et al., 2001). Turnover intention is one of the strongest predictors of an 
employee's likelihood to leave an organization (Allen, Weeks, \& Moffitt, 2005; Tett \& Meyer, 1993). If supervisor training can reduce employee turnover intentions, fewer employees are likely to leave the organization. This may result in decreased costs related to recruiting and training new employees.

One explanation for high levels of burnout and turnover in call center jobs is emotional labor (i.e., the process of managing personal feelings and expressions in order to fulfill the requirements of a job or task; Brotheridge \& Grandey, 2002; Montgomery, Panagopolou, de Wildt, \& Meenks, 2006). According to Rafaeli (1989) and others (e.g., Cordes \& Dougherty, 1993), burnout is one of the negative outcomes of emotional labor. The customer service industry is fraught with emotional labor because service interactions require employees to meet societal, occupational, and organizational expectations regarding the behaviors and emotions they display during service interactions (Ashforth \& Humphrey, 1993; Deery, Iverson, \& Walsh, 2002; Grandey, 2000; Hochschild, 1983). Display rules are often established by the organization to create consistent customer interactions. These expectations can include being friendly, smiling, and being helpful to customers (Grandey, 2003).

Customer service employees may have to display emotions that they do not sincerely feel in order to achieve work goals and satisfy customers (Diefendorff \& Gosserand, 2003). In the process, employees risk experiencing a disconnect between their true emotions and the emotions they are required to display (Morris \& Feldman, 1996). This disconnect, in combination with the frequency, duration, variety, and intensity of 
emotions required to perform the job determine the consequences of emotional labor (Morris \& Feldman, 1996). Interactions that are long and/or intense, and that require the display of various emotions, are less likely to be scripted (Hoschild, 1983). As a result, those types of interactions are likely to require greater effort and stamina on behalf of the employee in order to maintain displayed emotions (Hoschild, 1983). Thus, some forms of emotional labor can be more harmful than others.

Hochschild (1983) distinguishes two different types of acting in order to better clarify the emotional labor process: surface acting and deep acting. Surface acting requires the representative to display an emotion that he/she does not actually feel in order to meet the display rules required for the interaction (Hochschild, 1983). Deep acting occurs when the representative changes his/her inner feelings to match the emotion required for the interaction (Ashforth \& Humphrey, 1993). In their study, Ashforth and Humphrey (1993) found that only sincerely experienced emotions have beneficial outcomes for employees. This means that, while neither surface nor deep acting is ideal, surface acting is more detrimental to the employee.

Unfortunately, surface acting is a typical requirement of many call center customer service interactions because of the short duration and lack of established interpersonal relationship with customers. These characteristics are incompatible with the deep acting process, in which the employee would change his/her emotions to match those of the customer. Additionally, emotions can vary widely from one customer interaction to the next. In addition to burnout, negative outcomes of emotional labor 
include role overload (Wharton \& Erickson, 1993) and general dissatisfaction (Bailey \& McCollough, 2000), both of which can lead to withdrawal behaviors and turnover intentions (Bailey \& McCollough, 2000; Hochschild, 1983).

\section{The Supervisor as a Resource}

Some externally-provided resources, such as autonomy, may not be available in call center roles due to the largely regulated nature of the work; however, the supervisor may serve as an important resource in improving mental well-being outcomes for call center employees (Kelloway \& Barling, 2010). Supervisors are in a unique position to establish strong supportive relationships (Hammer, Wan, Brockwood, Bodner, \& Mohr, 2019; Nielsen \& Randall, 2009; Odle-Dusseau, Hammer, Crain, \& Bodner, 2016), identify signs that indicate employees may be struggling (Dimoff \& Kelloway, 2018, 2019), and intervene to help employees cope with job demands (Hammer et al., 2019; Nielsen \& Randall, 2009). Thus, supervisors are in a position to provide social support (i.e., psychological or material resources provided by family, friends, and/or coworkers; House, 1981).

There are four forms of social support: emotional, informational, instrumental, and appraisal (Cohen \& Wills, 1985; House, 1981; Langford, Bowsher, Maloney, \& Lillis, 1997). Emotional support involves conveying love, empathy, and compassion for the individual. Informational support involves providing information, guidance, and advice. Instrumental support occurs when tangible resources, such as financial assistance, are provided. Finally, appraisal support involves affirming one's self-evaluation. For 
example, when a supervisor assures an employee that they have the skills or knowledge to take on a project, he/she provides appraisal support. Social support can have a direct, moderating, or mediating effect on stressors and strain, according to social support theory (House, 1981). The direct effects model hypothesizes that individuals with high levels of social support display improved health as compared to those with low levels of support, regardless of the level of stress they experience (Cohen \& Wills, 1985). In the moderating, or "buffering," hypothesis of social support, support interacts with the stressors to reduce the level of strain (Viswesvaran, Sanchez, \& Fisher, 1999).

Supervisors, as part of an employee's workplace social support network, can help provide emotional, informational, instrumental, and appraisal support to employees (Dimoff \& Kelloway, 2013). This support is likely to be especially necessary for employees experiencing strain or other mental health issues (Holdsworth \& Cartwright, 2003). These employees are already experiencing demands and in need of resources. Social support, when provided to people experiencing strain, can be associated with positive outcomes, such as improved psychological well-being, positive affect, and more adaptive coping behaviors (Langford et al., 1997). Grandey (2000) proposes that supervisor support may buffer emotional labor by helping employees cope more adaptively with job demands.

The coping process begins with a) an appraisal of the demand or stressor, b) an assessment of potential responses to the demand or stressor, and c) some form of behavior (Carver, Scheier, \& Weintraub, 1989). Problem-focused coping involves 
behavior that seeks to eliminate or change the stressor (Carver et al., 1989); problemfocused coping is most successful when people feel they have control and can have a positive impact on the outcome (Carver et al., 1989). Conversely, avoidant coping puts the focus on the emotion rather than the stressor (Roth \& Cohen, 1986). Avoidant coping is characterized by behaviors that seek out social support, such as venting about the negative emotions and feeling helpless to change the outcome of the stressor. This causes behavioral and mental disengagement, which can lead to negative individual and organizational outcomes (Carver et al., 1989).

Social support can have a positive or negative impact on coping behaviors (Carver et al., 1989). In problem-focused coping, social support can facilitate active coping strategies to resolve the stressor; however, in avoidant-focused coping, social support can prolong venting behaviors and lead to helplessness. Therefore, supervisors may have an opportunity to influence the coping strategies subordinates enact to deal with workplace stressors through social support. Workplace coping interventions have been effective in modifying employee behaviors and are well documented in the literature (Butterworth, Linden, McClay, \& Leo, 2006; Klink, Blonk, Schene, \& Dijk, 2001; Martin, Sanderson, \& Cocker, 2009; Richardson \& Rothstein, 2008). The majority are secondary interventions, seeking to reduce the severity and duration of employee strain rather than prevent the strain from occurring (Richardson \& Rothstein, 2008). These interventions are overwhelmingly targeted toward the individual and vary in duration, frequency, and style of intervention (Bond \& Bunce, 2000; de Jong \& Emmelkamp, 2000). Yet, no 
interventions, to my knowledge, have specifically focused on improving employee coping abilities by training leaders to act as sources of social support.

In their meta-analysis, Klink and colleagues (2001) examined effect sizes based on intervention type and found that cognitive-behavioral (i.e., thought and emotionbased education aimed at developing adaptive coping skills) and multimodal interventions (i.e., incorporating cognitive-behavioral, relaxation, organizational change techniques into one intervention) produced the largest effect sizes. According to these findings, supervisory training that encourages supervisors to discuss specific coping strategies that are multimodal and cognitive-behavioral in nature may help call center employees engage in more adaptive coping strategies and experience less burnout (e.g., Leiter, 1991; Savicki, 2002).

\section{Training Supervisors to Support}

Workplace training interventions can be effective in improving individual wellbeing (Anger et al., 2015) and influencing organizational outcomes (Nielsen, Randall, Holten, \& Gonzalez, 2010). Leadership training, in particular, is critical to employee and organizational outcomes (Dimoff \& Kelloway, 2019; Hammer et al., 2019; Kelloway \& Barling, 2010; Nielsen \& Randall, 2009). Recent workplace mental health interventions focus on training leaders and individuals to identify and support employees who may be struggling with mental health challenges. The most widely researched of these interventions are Mental Health First Aid Training (MHFA; Kitchener \& Jorm, 2004) and Mental Health Awareness Training (MHAT; Dimoff, Kelloway, \& Burnstein, 2016). 
MHFA was developed to teach the public how to assist a person who is in crisis due to a mental health problem. The training has been evaluated in public, government, and organizational contexts and has been shown to increase individual mental health literacy and confidence in providing direct assistance to others (Kitchener \& Jorm, 2002, 2004, 2008). The training was not, however, developed specifically for the workplace context, nor was it focused on supervisors or managers. The MHFA course consists of approximately eight hours of in-person instruction, deeming it infeasible for many call center organizations because of the potential disruption to business operations.

Conversely, the MHAT was developed specifically for the workplace to help leaders identify and support employee mental health in the workplace (Dimoff \& Kelloway, 2019; Dimoff et al., 2016). The three-hour training focuses on support and resource mobilization for employees who may be struggling with mental health issues. Results show improved supervisor knowledge and attitudes about mental health and intent to promote mental health at work (Dimoff et al., 2016). Employees reported that their supervisors were more supportive of mental health issues and that they were more likely to use available mental health resources (Dimoff \& Kelloway, 2019). While these results are promising, the studies did not evaluate employee-level outcomes such as burnout, withdrawal behaviors, and turnover intentions. Therefore, the current study builds upon past MHAT research in evaluating the indirect impact of the program on employee coping behaviors and well-being. 
I hypothesize that by training supervisors to be more supportive of their call center employees' mental health, subordinates may perceive their supervisors as more supportive and engage in more problem-focused coping behaviors. I predict that employees whose supervisor attended the training will experience lower levels of burnout, display fewer withdrawal behaviors (i.e., absenteeism), and will be less likely to leave the organization (i.e., turnover intentions) as a result of the support provided by the trained supervisor (see Figure 1).

Hypothesis 1: Employees whose supervisor was in the intervention group will report increased supervisor support at Time 2 than employees whose supervisor was in the control group.

Hypothesis 2: Employees whose supervisor was in the intervention group will engage in increased problem-focused coping at Time 2 than employees whose supervisor was in the control group.

Hypothesis 3: Employees whose supervisor was in the intervention group will report lower burnout at Time 2 than employees whose supervisor was in the control group. 
Hypothesis 4: Employees whose supervisor was in the intervention group will exhibit improved attendance at Time 2 than employees whose supervisor was in the control group.

Hypothesis 5: Employees whose supervisor was in the intervention group will report decreased turnover intentions at Time 2 than employees whose supervisor was in the control group.

\section{Longitudinal Considerations}

In addition to testing the effectiveness of a supervisor mental health training on employees' perceived supervisor support, coping strategies, and well-being, this study explored the process through which a supervisor intervention can impact change on employee outcomes. Supervisor and employee attitudes and behaviors could be impacted by contextual variables, and therefore, any intervention-induced change may not be linear. I incorporated a weekly diary design to capture the process for behavioral and attitudinal changes among employees over the course of the study. Such an approach may provide a more nuanced understanding of the impact of the training and could broaden understanding. The following research questions were explored related to the diary study (see Figure 2):

Research Question 1: Does the trajectory of withdrawal intentions (i.e. turnover and absenteeism intentions) change in a linear or curvilinear fashion over time? 
Research Question 2: Does initial problem-focused coping and initial perceived supervisor support behaviors separately impact the trajectory of withdrawal intentions (i.e., turnover and absenteeism intentions) over time?

Research Question 3: Does the initial level of perceived supervisor supportive behaviors impact the initial problem-focused coping behaviors, thus impacting the trajectory of withdrawal intentions over time? 


\section{Method}

\section{Procedure}

To assess the effectiveness of a supervisor mental health support intervention on employee outcomes, a waitlist-control group design study was conducted in an outsourced call center organization located in Portland, Oregon. Organizations were recruited based on proximity to researchers and number of employees. To be eligible to participate, organizations must have had at least 20 managers, 200 employees, and be able to meet the timeframe of the study. One company's Chief Operating Officer responded to a general inquiry regarding research opportunities for supervisor mental health interventions and indicated that their organization would be willing and able to participate during the intended timeframe. No other interested organizations met the minimum size requirements and/or were unable to participate during the intended timeframe.

Survey distribution. The company required all of their call center supervisors to participate in the mental health training program as part of their management role. Supervisors were assigned to the intervention or waitlist-control group based on block randomization by location. The company had two call center locations, which operate independently, within the same metropolitan area. Block randomization was used to minimize operational disruptions to the organization and mitigate the risk of potential diffusion of treatment based on random assignment across locations (Suresh, 2011). All supervisors' employees were invited to participate in the research-portion of the study, 
but employees were not required to fill out the surveys. The Human Resources team provided a list of eligible employees, the name of their supervisors, and email addresses. I emailed employees an invitation to participate along with a link to the pre-training assessment survey (T1) three weeks before the intervention group training session and an identical electronic post-training assessment survey (T2) six weeks after the intervention group training (see Figure 3). The T1 emails were sent to participants using blind-copy; however, a firewall issue with the organization email server prevented the majority of recipients from receiving the invitation to participate. I worked with the company's IT department to set up internal, blinded distribution lists to increase deliver rates for subsequent survey distributions. As a result, initial participation was low and the intervention group training was postponed two weeks (See Figure 3 for data collection timeline). The data collection schedule for the remaining surveys was adjusted to reflect the delay, but the cadence of the survey distribution did not change. The three-hour training was delivered to the intervention group through a single in-person training session at the call center location. The training was conducted by one of the creators of the MHAT program who has delivered more than 100 training sessions to managers across North America and Europe. The waitlist-control group received the in-person training after data collection for the post-training assessment was complete. Participants had an equal amount of time to participate in the T1 and T2 surveys.

In addition to the pre- and post-training assessments, I conducted weekly diary surveys to evaluate the process of change related to the supervisor intervention. All 
employees were invited to complete short (i.e., 2-3 minute) weekly surveys during the six weeks following the intervention group training. The sixth diary survey was imbedded with the post-training assessment survey. All diary surveys were distributed electronically on Tuesdays because marketing research has demonstrated that it is the best day to send emails to avoid email fatigue effects that plague the beginning and end of the work week (Ellering, 2018). The survey prompt asked participants to reflect on their experiences "in the last week."

Participant matching over time. Each participant was prompted to create a unique identification number on all surveys (i.e., pre- and post-training assessments and diary surveys), which was used to match their individual responses across time points. Different electronic survey links were used for the intervention and control groups and participants provided their location and team name on the pre- and post-training assessments to ensure they were categorized into the appropriate condition.

Participant recruitment and retention efforts. Attrition and low sample size are common issues in intervention research (Kelloway \& Barling, 2010). Several strategies were employed to boost employee participation in the study. First, I met with the Chief Operating Officer, Director of Human Resources, and Director of Organizational Development to gain organizational buy-in for the project and understand the feasibility of administering surveys over the course of the study. They indicated that the employees were familiar with, and willing to participate in workplace surveys. The Chief Operating Officer sent an email to participants during each of the T1 and T2 surveys to express her 
support of the research and encourage participation. Second, I conducted "meet-theresearcher" events at each location during the T1 survey. The goal of these events was to allow employees to ask questions about the procedures, anonymity, and confidentiality associated with the research study. The specific purpose of the study was not discussed in any more detail than what was included in the surveys' informed consent document. Snacks were provided in the community break room of each location during the event. Approximately 15-20 employees attended at each location.

Finally, employees were incentivized to complete each of the seven surveys (i.e., pre-test, post-test, and 5 diary surveys). Employees were invited to enter their email address in a form, at the completion of each survey to register for a prize drawing. Email addresses were stored separately from survey responses to maintain participant anonymity. Each week, a survey winner was selected, at random, to receive a gift basket valued at approximately $\$ 30$. I assembled and delivered each gift basket to the work location of the winning participant.

The training intervention. The Mental Health Awareness Training (MHAT) program (Dimoff \& Kelloway, 2019; Dimoff et al., 2016) formed the foundation for the training intervention used in this study. The one-time, three-hour training teaches supervisors to identify and support employees who are struggling with mental well-being at work. The training consists of two lecture-based modules and highly interactive case studies and videos. The training was designed and delivered according to the recommendations of the National Institute of Occupational Safety and Health (NIOSH; 
Sauter et al., 1992). The scope of training is support within the context of the supervisor role. The emphasis is detection of warning signs that impact the workplace and/or individual performance of the employee, rather than the diagnosis of mental illness.

Training customization. The training was customized to meet the relevant needs of the call center organization, as is standard with the MHAT training protocol (Dimoff \& Kelloway, 2019). I conducted an in-depth needs assessment in partnership with the Director of Organizational Development and key human resources stakeholders to identify organizational needs and current resources. I reviewed job descriptions for the supervisor and employee roles, relevant employee handbooks and policy documents, and met with the Chief Operating Officer. I conducted one-on-one interviews with two supervisors in the intervention group and a two-on-one interview with two supervisors in the control group to understand the situations and challenges that supervisors face in supporting the related to the mental health of their direct reports.

The needs assessment identified burnout, emotional labor, and "resources" to support employees' adaptive coping strategies as opportunities for customization within the MHAT training. The Chief Operating Officer cited high turnover rates and frequent instances of employees requesting to leave early due to emotional distress as metrics of concern. As evidence of emotional labor, one supervisor said: "We heavily emphasize the friendliness of employees. It's hard to sound happy when you have bad stuff going on." Additionally, there are more than 11 references to the appropriate "[company name] tone" for interacting with customers and coworkers, including a list of phrases that 
employees should adopt to represent the "[company name] way" in the company's 26page employee handbook. Problem-focused coping strategies may help reduce the negative effects of conforming to the display rules and surface acting required to fulfill the call center representative role (Deery et al., 2002; Grandey, Dickter, \& Sin, 2004). The supervisor interviews also consistently cited lack of knowledge of available resources as a difficulty in supporting employees. One supervisor said: "It's an uncomfortable conversation for me. I wish I knew more resources to share.”

Training content. The first part of the training focused on "starting the conversation" about workplace mental health and introduces warning signs that supervisors should recognize in struggling employees. The 30 -minute case study used in the first section was customized to a call center scenario in which the employee was uncivil towards a customer and made a number of mistakes in the call handling procedure. Condensed brainstorming sessions were used to encourage supervisors to use knowledge and experiences they already had and expand their existing knowledge-base. Mental health topics covered in the first section of the training included burnout, strain, emotional labor (i.e., surface acting and deep acting), depression, anxiety, and substance abuse.

The second part of the training revolved around "taking action." A short module on suicide was added, at the request of the company. Supervisors tailored existing skills in the context of employee mental health and built new skills related to supporting and coaching subordinates in problem-focused coping strategies and emotional labor. 
Interactive case studies, videos, and discussion among participants were incorporated to promote active learning and practice. The content focused on a) assisting employees demonstrating warning signs of struggle (e.g., what to say to an employee, how to support employees at work, and when to engage other resources), b) cognitive-behavioral exercises managers can use to coach employees (e.g., positive psychology and brainstorming), and c) accommodating and managing employees (e.g., accommodations to help employees stay at work and resources such as EAP). Several existing company resources were discussed in the training, including promoting the company health insurance plan, employee assistance program (EAP), on-site fitness classes, and professional development workshops. Supervisors were coached to help their employees cope more adaptively in a number of ways. For example, supervisors should educate employees about emotional labor, including the negative ramifications of surface acting and strategies for moving toward deep acting, including attempting to find meaning in the work. Other coping strategies include taking short "microbreaks" (i.e., less than a minute) to detach after an emotionally-difficult customer interaction (Fritz, Lam, \& Spreitzer, 2011). Supervisors were taught how to coach employees to use an organization-provided gratitude and reflection journal; specifically, supervisors were taught how to coach employees to use the journal for brief perspective-taking exercises in alignment with mindfulness practice (Langer \& Moldoveanu, 2000). Supervisors received a binder of training materials which included the slides, case studies, information on relevant mental 
health resources, and a one-page overview document designed to be displayed in their workspace for easy reference when interacting with employees.

\section{Participants}

The employees $(N=314)$ of supervisors in the company's two call center locations were invited to participate in the study. Invitations to participate were sent three weeks before the first training session. The company's Human Resources department informed me that one supervisor in the control group left the organization during the study. We were not informed of any employee departures during the study; however, we expected natural attrition because the company disclosed a $30 \%$ annual turnover rate for call center employees during initial discussions. Of those invited, 163 employees completed the T1 pre-assessment (84 in the intervention group and 79 in the control group) and 94 completed the T2 post-assessment (56 in the intervention group and 38 in the control group). The total number of participants who took the assessments at both time points was 74 (23\% response rate; 44 intervention group and 30 control group participants). The intervention group was $68.2 \%$ female; the control group was $80 \%$ female. The mean tenure was 14.7 months for the intervention group and 19.4 months for the control group. In the intervention group, $45.5 \%$ of participants self-identified as LGBT; in the control group, $30 \%$ of participants self-identified as LGBT. Demographic statistics are presented in Table 1. 


\section{Measures}

Pre- and post-training assessment measures. The assessment survey was administered to all study participants three weeks prior to the intervention group training (T1) and six weeks after the training (T2). Each participant received the same survey items at each of the two measurement periods. Appendix A contains the employee measures for the pre- and post-assessment survey. Correlation and reliability estimates for all measurement scales are presented in Tables 2 and 3.

Demographics. Demographic and control variables were established using standard survey questions that ask about participants' age, gender, tenure with the company, work location (i.e., intervention or control), and personal experience with mental health. Experience with mental health was assessed using the item: "Have you or a close friend or family member ever suffered from any mental health problem?" Employees were asked to rate the frequency with which they interact with their supervisor and provide their team name.

Perceived supervisor support. Eight items from the Survey of Perceived Organizational Support (SPOS; Eisenberger et al., 1986) were adapted to measure perceived supervisor support. In the same manner as others, the term organization was replaced with supervisor (DeConinck, 2010; Rhoades, Eisenberger, \& Armeli, 2001). Respondents rated each statement on a 6-point Likert scale ranging from 1 ("strongly disagree") to 6 ("strongly agree"). A sample item was "My supervisor really cares about my well-being." 
Perceived supervisor behaviors. Supervisor behaviors related to promotion of mental health in the workplace and employee mental health were measured using an 11item employee perceptions of supervisor behavior scale (Dimoff et al., 2016). Employees used the same 6-point Likert scale ranging from 1 ("strongly disagree") to 6 ("strongly agree"). A sample item from the employee perception scale was "My supervisor takes the time to talk to me when I am upset."

Burnout. Burnout was measured using 16 items from Maslach's Burnout Inventory scale (MBI; Maslach \& Jackson, 1986), which measures burnout on the dimensions of emotional exhaustion, depersonalization, and personal accomplishment. Respondents indicated the frequency with which they experience feelings of burnout on a 6-point Likert scale from 1 ("never") to 6 ("very frequently"). A sample item included "I feel emotionally drained from my work."

Coping. The 28-item Brief COPE (Carver, 1997) scale was used to measure employee problem- and avoidant-focused coping. The self-report measure evaluates actions and feelings on 14 patterns of coping using a 4-point Likert scale ranging from 1 ("I usually don't do this at all") to 4 ("I usually do this a lot"). The patterns associated with problem-focused coping are: active coping, planning, and using instrumental support (Carver, 1997). A sample problem-focused coping item was "I concentrate my efforts on doing something about it." The patterns associated with avoidant-focused coping are: venting, behavioral disengagement, and self-distraction (Carver, 1997). A sample 
avoidant-focused coping item was "I admit to myself that I can't deal with it, and quit trying."

Turnover intentions. Turnover intentions were measured using three items adapted from Konovsky and Cropanzano (1991). Employees evaluated their intentions to leave the organization using a 6-point Likert scale ranging from 1 ("strongly disagree") to 6 ("strongly agree"). A sample item was "I often think about quitting my job."

Attendance. Attendance was measured using data provided by the company from the electronic attendance management system used to track employee time. The system uses codes to track hours of various uses of employee time. The "receptionist time" code represents hours worked and was used as a measure of employee presence at work. The codes related to withdrawal behaviors were "sick time", "unpaid leave time", and "excused unpaid time", because these codes do not require advance notice for use, based on descriptions provided by human resources representatives. "Paid time off" and codes related to long-term leave statuses were excluded because company policy requires those classifications to be planned and approved in advance of the absence.

Weekly diary survey. The purpose of the diary survey was to measure employees' attitudes, problem-focused coping strategies, and perceptions of their supervisors' supportive behaviors related to the content of the training. Consistent with previous studies (Schreurs, Hetty van Emmerik, Günter, \& Germeys, 2012), I selected a weekly cadence diary method because daily intervals may not be long enough to detect attitudinal and behavioral change over time. In recent years, intervention studies have 
been criticized for a lack of process evaluation (Murta, Sanderson, \& Oldenburg, 2007). Thus, a six-week lag time between the pre- and post-training assessments could mask meaningful information about the process of change that is triggered by the training program. This study sought to not only understand the longer-term impacts of a supervisor-focused training, but also to capture how attitudes and behaviors in the shortterm explain longer-term outcomes. The weekly diary assessed employee coping and turnover intentions. The short survey focused on behavioral and reflection items. It also included an optional open-ended question for participants to provide context to their perceptions and behaviors of the previous week.

Measures. Appendix B contains the measures for the weekly diary questionnaire. The survey prompt asked employees to reflect on their experiences and attitudes over the "last week."

Struggle identification. One item measured whether the supervisor noticed and acknowledged a struggling employee. The question asked "Did your supervisor notice if/when you encountered a challenge this week?" Response options included "yes," "no," and "No, because this didn't happen to me this week."

Supervisor support behaviors. Employees identified their supervisor's supportive behaviors during the week using 11 items adapted from the supervisor support behaviors scale to reflect supervisor behaviors that were relevant to the training (Dimoff et al., 2016). A sample item was "He/She/They suggested I use the Employee Assistance Program (EAP).” 
Coping. Eight items measured employees' coping strategies with a struggle that week. Four items represented problem-focused coping characteristics (e.g., "I took action to try to make the situation better") and four items measured avoidant-focused coping characteristics (e.g., "I tried not to think about it"). Participants rated their agreement on a 6-point Likert scale from 1 ("not at all agree") to 6 ("completely agree").

Withdrawal intentions. One item measured employee withdrawal intentions using a 6-point Likert frequency scale ranging from 1 ("never") to 6 ("very frequently"). The item was: "This week, how often did you feel like leaving work early or avoiding calls because you were struggling?".

Turnover intentions. Employee turnover intentions were measured using one item on a 6-point Likert scale ranging from 1 ("strongly disagree") to 6 ("strongly agree"). The item was: "This week, I seriously considered looking for a new job."

\section{Analyses}

Power analysis. A power analysis was conducted using $\mathrm{G}^{*}$ Power (Faul, Erdfelder, Lang, \& Buchner, 2007). Results determined that a sample size of 128 employee participants was necessary to achieve a medium effect size of .25 for a repeated measures MANOVA for time (pre- and post-training assessments) by treatment (control vs. intervention) interactions. Of the 314 employees whose supervisors participated in the training intervention, only $74(23.5 \%)$ employees completed the assessments at both time points. 
Attrition analyses. Although attrition is a common issue in field-based intervention research, it was particularly problematic in this sample due to several constraints unique to the organization (e.g. time constraints on employees; see discussion and limitations section). Of the 163 participants who completed the T1 assessment, only 74 completed the $\mathrm{T} 2$ assessment six weeks later. This represents a $54.6 \%$ attrition rate for participants who completed the T1 assessment. High attrition rates in this sample resulted in decreased power to detect effects of the training, generalizability of the findings, and could potentially lead to biased findings. For example, if only participants interested in mental health participated at both time points, findings may be misrepresentative of the overall sample. Similarly, if attrition is disproportionate across groups or leads to systematic differences in participant demographics, attrition can lead to bias conclusions surrounding the impact of the training. I conducted attrition and missing data analyses using data from all participants who completed at least one of the assessments (see Table 8). Through this process, I was able to investigate whether there were patterns associated with participant dropout and missing data for the sample (Schafer \& Graham, 2002).

A chi-square test was used to determine whether there was a significant difference between treatment conditions in the participants who responded to the survey at T2. Only $39.4 \%$ of participants in the control condition at T1 completed the T2 survey, while $57.0 \%$ of participants in the intervention group at $\mathrm{T} 1$ participated at $\mathrm{T} 2$. This difference was statistically significant, $\chi^{2}=6.53, \mathrm{p}<0.05$, and indicated that participants in intervention group were less likely to drop out of the study than participants in the control 
group. The phi coefficient, $\phi=0.18$, indicated a small to moderate effect. Independentsamples $t$-tests were computed, using SPSS, to determine if there were differences in the demographics and profiles of participants who completed the T2 survey. There were no significant differences in age or T1 scores on the outcomes variables of supervisor support, supervisor supportive behaviors, burnout, or turnover intentions between those who completed the T2 survey and those who dropped out. Chi-square tests were conducted to evaluate whether gender or self-identified LGBT-status impacted the likelihood of participants to drop out of the study. Results indicated that $74.0 \%$ of participants who completed the T2 survey were women, while $67.1 \%$ of those who dropped out after the T1 survey were women. Thirty-eight percent of T2 survey participants self-identified as LGBT while $41 \%$ of those who dropped out between surveys self-identified as LGBT. These gender and LGBT-identity differences were not significant, $\chi^{2}=2.39$, ns, and $\chi^{2}=6.76$, ns, respectively. These results indicated that there did not appear to be patterns in the characteristics or demographics of employees who participated or dropped out of the study.

Sample Analysis. A one-way MANOVA was conducted to determine if there were group differences between the two groups on the dependent variables and six potential covariates at T1 (i.e., gender, age, LGBT, tenure with company, frequency of interaction with supervisor, and personal experience with mental illness). Results indicated that the groups were not significantly different at $\mathrm{T} 1(F=1.08, n s)$. Univariate 
ANOVA tests were examined and indicated that there were no significant group differences on any of the individual variables at $\mathrm{T} 1$ for the two groups.

Hypothesis analyses. To test the impact of the training, I used SPSS to perform a repeated measure MANOVA designed to evaluate group differences over time using five dependent variables (i.e., perceived supervisor support, supervisor supportive behaviors, problem-focused coping, burnout, and turnover intentions). To test hypotheses 1-3 and 5, univariate ANOVA tests were examined to determine if there were differences between the intervention and control groups at T2. To test hypothesis 4 , independent samples $t$ tests were used to compare attendance performance of the intervention and control groups at $\mathrm{T} 2$ on the measures outlined above (i.e., receptionist time, sick time, unpaid leave time, and excused unpaid time).

Diary analyses. Growth curve models were used to evaluate the trajectory in change of behavior over time for employees in the six weeks following the training intervention. Because each participant was measured at six time points post-training (i.e., weekly diary surveys), the data were a) nested within person, and b) dependent on the previous week's measurement. Thus, a hierarchical linear modeling approach was appropriate (Hox, 2002). I conducted the analyses in SPSS version 25, using REML estimation and the GENLINMIXED procedure and robust standard errors. I examined whether turnover and absenteeism intentions have a linear or curvilinear change over time. To do so, I conducted two separate series of growth curve models with turnover intentions and absenteeism intentions as the dependent variables, respectively, and time 
as the independent variable. Specifically, time was coded as 0 at the first diary measurement occasion (i.e., the first week following the supervisor training) so that the effect demonstrated the intercept at the first measurement. I examined whether the initial levels of coping and perceived supervisor support behaviors separately impact the trajectory of change (i.e., whether or not coping and perceived support moderate the relationship between time and turnover and absenteeism intentions). Finally, I examined whether the initial amount of perceived supervisor support behaviors impacted the initial level of coping, thus impacting the relationship between time, turnover, and absenteeism intentions (i.e., three-way interaction between perceived support, coping, and time on turnover and absenteeism intentions, respectively). 


\section{Results}

A repeated-measures MANOVA did not result in significant group $\mathrm{x}$ time interaction for employees $\left(F=.66, n s\right.$, partial $\left.\eta^{2}=.05\right)$. However, the univariate results of repeated measures MANOVA were still inspected, so as to explicitly evaluate Hypotheses 1-3 and 5. Results indicated there were no significant differences in perceived supervisor support $\left(F(1,68)=.06, n s\right.$, partial $\left.\eta^{2}=.00\right)$, perceived supervisor supportive behaviors $\left(F(1,68)=1.00, n s\right.$, partial $\left.\eta^{2}=.01\right)$, problem-focused coping $\left(F(1,68)=1.29, n s\right.$, partial $\left.\eta^{2}=.02\right)$, burnout $\left(F(1,68)=.73, n s\right.$, partial $\left.\eta^{2}=.01\right)$, or turnover intentions $\left(F(1,68)=.89, n s\right.$, partial $\left.\eta^{2}=.01\right)$ between the intervention and control group as a result of the supervisor training intervention. Thus, hypotheses 1-3 and 5 were not supported. Means and standard deviations for each dependent variable are reported in Table 4.

Given the high levels of attrition and the significant differences in participation between the intervention and control groups at T2, I conducted multiple imputation (MI) in SPSS to evaluate the extent to which this study's findings may have been impacted by missing data. Specifically, the goal of MI, in this case, was to evaluate whether the findings would be different if all participants $(N=211)$ were included in the analyses, as compared to listwise deletion $(N=74)$, wherein which only scores for participants who completed surveys at T1 and T2 would be included. I performed linear regression on each of the dependent variables (i.e., supervisor support, supervisor supportive behaviors, problem-focused coping, burnout, and turnover intentions) across 25 imputed datasets 
(Wang \& Johnson, 2019). The results of the pooled regression analyses were consistent with those of the univariate ANOVA tests performed on the listwise deletion dataset (see Table 9). Therefore, the analyses reported in the Results section are based on listwise deletion with a final sample size of $N=74$.

Independent samples $t$-tests were conducted to determine whether there was a significant difference in attendance performance between the intervention and control groups at T2. Results indicated that there was not a significant difference between the two groups in the number of hours employees worked, $(M=367.04, S D=82.91$ for intervention; $M=367.36, S D=73.71$ for control, $t(219)=.03, n s)$, sick time $(M=20.22$, $S D=10.96$ for intervention; $M=21.35, S D=12.38$ for control, $t(208)=.70, n s)$, unpaid leave $(M=7.37, S D=8.09$ for intervention; $M=6.08, S D=6.14$ for control, $t(56)=-$ $.65, n s)$, or excused unpaid leave $(M=25.00, S D=19.35$ for intervention; $M=29.76, S D$ $=23.32$ for control, $t(25)=.56, n s)$, in the three months following the intervention. Thus, hypothesis 4 was not supported.

\section{Longitudinal Research Questions}

Growth curve models were tested to evaluate the trajectory of change in withdrawal intentions (i.e., turnover and absenteeism intentions) over time. The number of participants for each analyses ranged from 324 to 523 (see Tables 5 - 7). Turnover intentions and time were included in the first model. The intercept fixed effect was 2.27, which was the average turnover intention score for employees one week following the supervisor training. Baseline values of turnover intentions varied significantly among 
individuals, $\tau_{0}^{2}=4.09, z=4.96, \mathrm{p}<0.001^{1}$. Turnover intentions increased by 0.02 on average over the subsequent five weeks; however, the fixed effect for time was not significant, $\gamma_{10}=0.02$, ns. The variance of time was also significant, $\tau_{1}{ }^{2}=0.14, z=2.64, p$ $<0.01$, indicating that the rate of change in turnover intentions varied across individuals. The covariance between turnover intentions and time was significant, $\tau_{01}=-0.61, z=-$ $3.16, \mathrm{p}<0.01$, which indicates that turnover intentions of individuals with lower initial levels of turnover intentions increase more rapidly than individuals with higher initial levels of turnover intentions. Absenteeism intentions and time were included in the second model. The intercept fixed effect was 3.70, which was the average absenteeism intention score for employees one week following the supervisor training. Baseline values of absenteeism intentions varied significantly among individuals, $\tau_{0}^{2}=3.55, z=$ 5.33, $\mathrm{p}<0.001$. Absenteeism intentions increased by 0.03 on average over the subsequent five weeks; however, the fixed effect for time was not significant, $\gamma_{10}=0.03$, ns. The variance of time was significant, $\tau_{1}^{2}=0.14, z=-3.95, p<0.01$. The covariance between absenteeism intentions and time was significant, $\tau_{01}=-0.57, z=-3.97, \mathrm{p}<0.01$, which indicates that individuals with lower initial absenteeism intention levels increase more rapidly than individuals with higher initial levels. Results indicated that time was not a significant predictor of change in turnover or absenteeism intentions; therefore, research question 1 was not supported.

\footnotetext{
${ }^{1}$ Significance tests for variance of intercepts and slopes were conducted based on one-tailed tests, as recommended by Snijders and Bosker (2012).
} 
Growth curve models were tested to evaluate the impact of initial levels of supervisor supportive behaviors and problem-focused coping on withdrawal intentions (i.e., turnover and absenteeism intentions). Initial supportive behaviors and problemfocused coping were centered around the grand mean to improve interpretation of the intercept. The cross-level interaction between the centered supportive behaviors and time were included in the models. Supportive behaviors and turnover intentions were evaluated in the first model. The intercept fixed effect was 2.25 , which was the average turnover intention for participants whose supervisors engaged in average supportive behaviors. Initial supportive behaviors varied significantly across participants, $\tau_{0}^{2}=3.80$, $z=5.23, \mathrm{p}<0.001$. The fixed effects for supportive behaviors, time, and the interaction between supportive behaviors and time were not significant, $\gamma_{01}=0.32$, ns, $\gamma_{10}=0.04$, ns, $\gamma_{11}=0.15, \mathrm{~ns}$, and indicated that on average there was not a significant change in turnover intention, main effect for supportive behaviors, and that change in turnover intentions did not depend on supervisor supportive behaviors. The variance of the slope was significant, $\tau_{1}^{2}=0.10, z=2.66, \mathrm{p}<0.01$. The covariance between intercept and slope was significant $\tau_{01}=-0.43, z=-3.01, \mathrm{p}<0.01$. The second model tested the impact of initial problem-focused coping on turnover intentions over time. The intercept fixed effect was 2.05, which was the average turnover intention at baseline for participants who engaged in average problem-focused coping. Initial problem-focused coping varied significantly across participants, $\tau_{0}^{2}=3.67, z=5.28, \mathrm{p}<0.001$. The fixed effects for problem-focused coping, time, and the interaction between problem-focused coping and 
time were not significant, $\gamma_{01}=0.15$, ns, $\gamma_{10}=0.05$, ns, $\gamma_{11}=0.01$, ns. The variance of the slope was significant, $\tau_{1}^{2}=0.11, z=2.77, \mathrm{p}<0.01$. The covariance between intercept and slope was significant, $\tau_{01}=-0.42, z=-3.03, \mathrm{p}<0.01$.

The third model tested the impact of supportive behaviors on absenteeism intentions. The intercept fixed effect was 3.68, which was the average absenteeism intention for participants whose supervisors engaged in average supportive behaviors. Initial supportive behaviors varied significantly across participants, $\tau_{0}^{2}=3.05, z=5.30, \mathrm{p}$ $<0.001$. The main effects for supportive behaviors and time were not significant, $\gamma_{01}=$ $0.06, \mathrm{~ns}, \gamma_{10}=0.05$, ns. The cross-level interaction between supportive behaviors and time was significant, $\gamma_{11}=0.34, p<.05$, however. The variance of the slope was significant, $\tau_{1}^{2}=0.12, z=3.75, \mathrm{p}<0.01$. The covariance between intercept and slope was significant $\tau_{01}=-0.47, z=-3.77, \mathrm{p}<0.01$.

The fourth model tested the impact of initial problem-focused coping on absenteeism intentions over time. The intercept fixed effect was 3.63 , which was the average absenteeism intention for participants who engaged in average problem-focused coping. Initial problem-focused coping varied significantly across participants, $\tau_{0}^{2}=2.68$, $z=5.03, \mathrm{p}<0.001$. The fixed effects for problem-focused coping was significant, $\gamma_{01}=$ $0.45, \mathrm{p}<0.01$; however, time and the interaction between problem-focused coping and time were not significant, $\gamma_{10}=0.06$, ns, $\gamma_{11}=-0.05$, ns. The variance of the slope was significant, $\tau_{1}{ }^{2}=0.12, z=3.48, \mathrm{p}<0.01$. The covariance between intercept and slope was significant, $\tau_{01}=-0.41, z=-3.36, p<0.01$. Based on the results from four growth curve 
models, initial levels of supervisor supportive behaviors or problem-focused coping do not significantly predict the trajectory for change in withdrawal behaviors over time. Research question 2 was not supported.

Growth curve models were tested to evaluate the impact of initial supervisor supportive behaviors on initial problem-focused coping levels and the subsequent impact on the trajectory of withdrawal behaviors (i.e., absenteeism and turnover intentions). All two-way interactions and main effects were included in the models. As with research question 2, initial supportive behaviors and initial problem-focused coping were centered around the grand mean for ease in interpretation of the intercept coefficient. The first model tested the three-way interaction related to absenteeism intentions. The intercept fixed effect was 3.61, which was the average absenteeism intention measure for participants with average supervisor supportive behaviors and problem-focused coping. The fixed effect for supervisor supportive behaviors was not significant, $\gamma_{10}=0.53$, ns; however, the fixed effect for problem-focused coping was significant, $\gamma_{10}=0.40, p<$ 0.05 , and indicated that absenteeism intention increased by 0.40 for each point increase in problem-focused coping. The fixed effect for time was not significant, $\gamma_{10}=0.08$, ns. The interaction between initial supportive behaviors and problem-focused coping were not significant, $\gamma_{10}=0.20$, ns. Similarly, the interaction between problem-focused coping and time was not significant, $\gamma_{10}=-0.05$, ns. The variance of the slope was significant, $\tau_{0}^{2}=$ $0.12, z=3.57, \mathrm{p}<0.001$. Finally, the three-way interaction of initial supportive behaviors, initial problem-focused coping, and time was not significant, $\gamma_{10}=-0.21$, ns. 
The covariance between the intercept and slope was significant, $\tau_{01}=-0.43, z=-3.50, p<$ 0.001, which indicated that the trajectory of absenteeism intentions varied across participants.

The second model tested the interaction among initial supportive behaviors, initial problem-focused coping, and turnover intentions. The intercept fixed effect was 2.23, which was the average turnover intention measure of participants with average supervisor supportive behaviors and problem-focused coping. The fixed effects for initial supportive behaviors, initial problem-focused coping, and time were not significant, $\gamma_{01}=0.33$, ns, $\gamma_{10}=0.14$, ns, $\gamma_{11}=0.07$, ns. The variance of the slope was significant, $\tau_{0}^{2}=0.10, z=$ $2.76, \mathrm{p}<0.01$. The interaction between initial supportive behaviors and initial problemfocused coping was not significant, $\gamma_{10}=0.01$, ns, and neither was the interaction between initial problem-focused coping and time, $\gamma_{10}=-0.14$, ns. The three-way interaction among initial supportive behaviors, initial problem-focused coping, and time was also not significant, $\gamma_{10}=-0.11$, ns. The covariance between the intercept and slope was significant, $\tau_{01}=-0.43, z=-3.08, \mathrm{p}<0.01$, which indicated that those low in initial turnover intentions increased at a faster rate than those high in initial turnover intentions. Research question 3 was not supported, as there were no significant interactions among initial supervisor supportive behaviors, initial problem-focused coping, and absenteeism or turnover intentions (i.e., withdrawal intentions). 


\section{Discussion}

The purpose of this study was twofold: 1) to evaluate the impact of a supervisor mental health intervention on call center employee attitudes and behaviors, and 2) to provide insight into the process by which the training impacts employee attitudes and behaviors. While previous studies evaluated the direct and indirect impacts of training on supervisor outcomes (Dimoff \& Kelloway, 2019; Dimoff et al., 2016; Kitchener \& Jorm, 2008), this study investigated the indirect impact of supervisor training on subordinates. The results from this study indicated that there were no indirect effects of the supervisor mental health training on employee outcomes related to perceived supervisor support, adaptive coping strategies, burnout, attendance, and turnover intentions. There are several potential explanations for these non-significant findings that warrant further discussion low power to detect effects, possible ceiling effects on perceived supervisor support, inconsistent or insufficient recognition of supportive supervisor behaviors, challenges related to the call center context, and a possible lack of training transfer.

Many longitudinal intervention studies suffer from high rates of participant attrition (Kelloway \& Barling, 2010), and this sample was no exception. Despite efforts to retain participants, the final samples size did not provide sufficient power to detect moderate training effect sizes. I used several strategies to engage participants in an attempt to improve survey response rates over the course of the study. These strategies included gaining and communicating executive support for the project, conducting "meet the researcher" sessions at each research site (i.e., intervention and control group call 
center locations) to answer questions, and incentivizing participants with random drawings for prizes in exchange for completing surveys. The Director of Organizational Development was surprised by the low participation rates. We discussed the importance of achieving high response rates in order to ensure the results were representative of the organization at the project onset, and I was assured that employees would have adequate time to complete the surveys. However, in the "meet the researcher" sessions, employees cited high performance expectations (i.e., number of calls per day performance metrics) as a stressor that prevented them from taking breaks and completing the surveys. High levels of attrition resulted in an under-powered sample from which I was unable to garner statistically significant effects.

In addition to power concerns, it is possible that non-significant effects were related to a variety of other methodological issues, such as the operationalization of social support. According to the stress buffering model of social support, social connections provide emotional, instrumental, and informational support to facilitate adaptive coping behaviors (e.g., problem-focused coping) and reduce negative outcomes associated with prolonged exposure to stress (e.g., burnout, turnover intentions, and withdrawal behaviors; Cohen, 2004). Thus, social support is capable of a) buffering the negative impacts of difficult situations, and b) facilitating proactive coping behaviors during difficult situations (Cohen, 2004; Cohen \& Wills, 1985). As a result, social support can help to initiate a cascade of positive outcomes (e.g., Dimoff \& Kelloway, 2019; Hobfoll, 2011). In this study, a potential ceiling effect (i.e., the independent variable no longer has 
an effect on a dependent variable; Taylor, 2012) related to supervisor support may have been partially responsible for the lack of difference between the intervention and control groups, because perceived supervisor support was remarkably high among supervisors in the training and control groups at T1. These already high levels of perceived supervisor support within both groups may have made it difficult for the training to initiate a process by which improvements in social support facilitate improvements in other outcomes. Given that improvements in supervisor support were expected to facilitate improvements in other outcome variables (e.g., supervisor supportive behaviors), the lack of improvement in supervisor support may have prohibited observation of more downstream training impacts (e.g., employee burnout and absenteeism). For instance, prior research has demonstrated that the MHAT program exhibits a pattern of both direct and indirect effects (Dimoff et al., 2016), whereby the training impacts certain variables directly (e.g., knowledge), which then facilitate improvements in other variables (e.g., stigma).

In the present study, the weekly diary component was designed to help capture this pattern of effects, with the expectation that the training would facilitate improvements in perceived supervisor support, which would help facilitate improvements in a variety of other outcomes, such as behavior changes among employees. Unfortunately, while perceived supervisor support may have involved a possible ceiling effect within both the control and experimental groups, enacted supervisor support was low. Employees in both groups reported that their supervisor did not engage in specific supportive behaviors frequently throughout the study. These results did not support the 
hypotheses. Given prior findings (i.e., Dimoff \& Kelloway, 2019; Dimoff et al., 2016), I predicted that leaders in the intervention group, when compared to leaders in the control group, would engage in significantly more support behaviors. Supervisors in the intervention group were trained to engage in a variety of very specific behaviors designed to a) provide support to struggling employees (e.g., suggesting the EAP; Dimoff \& Kelloway, 2019) and b) help employees engage in proactive coping behaviors (e.g., encouraging microbreaks; Fritz, Ellis, Demsky, Lin, \& Guros, 2013). Despite this highly specific training and the levels of perceived supervisor support at T1, employees did not report observing high frequencies of supportive behaviors in their supervisors. This misalignment in findings (i.e., high endorsement of perceived supervisor support, but low endorsement of supervisor supportive behaviors) may be related to a disconnect between the operationalization of perceived supervisor support and the actual supervisor behaviors that were measured in this study (Thoits, 1982).

At each data collection point in the study (i.e., pre-test, post-test, and at each of the 5 weekly diary time points), I measured employees' perceptions about supervisor support and employees' observations of specific supervisor supportive behaviors. While the measure capturing perceptions about supervisor support measured employees' beliefs about how supportive their leader was, leaders' actual behaviors were captured using an 11-item list of behaviors (see Appendix A). Although each of the behaviors in this list was targeted during the 3-hour training, employees in neither group reported that their supervisors engaged in the trained behaviors at a particularly high frequency. These 
findings may be the result of four possible processes. First, it is possible that, even in the absence of specific supportive behaviors, employees felt generally supported by their supervisors. High endorsement of attitudinal measures, with corresponding low endorsement of specific behavioral measures helps to reduce the likelihood of a possible halo effect (i.e., unconscious appraisal of behavior based on an overall positive impression; Thorndike, 1920), whereby all employees would have reported that their leader, whom they already felt positively about, showed specific support at work.

A second explanation may be that the behavioral measures of supervisor support inadequately captured supervisor support behavior. It is possible that leaders engaged in other types of support behaviors that were not represented on the survey, representing an issue with construct validity (Bagozzi, Yi, \& Phillips, 1991). Similarly, it is possible that employees liked their supervisors, leading them to respond to the perceived support scale items more favorably (i.e., social desirability; Fisher, 1993). Conversely, the behavioral items were more ambiguous (e.g., "my supervisor recognizes when I am having a difficult time") and it may not have been especially clear to employees as to whether or not a positive endorsement of the behavior would reflect positively on their supervisor. This ambiguity may have led to low to neutral endorsement of all items (Einhorn \& Hogarth, 1986).

Third, it is possible that too much was expected of leaders, given that this was a brief, one-time intervention (Okhuysen \& Eisenhardt, 2002). Compared to previous studies evaluating the MHAT (Dimoff \& Kelloway, 2019; Dimoff et al., 2016), this study 
required extensive customization related to leader behaviors. Rather than merely training leaders to be more knowledgeable about mental health issues, less stigmatizing of mental illness, and more confident with regard to supporting employee mental health, leaders were also trained to coach employees to cope with stressors more adaptively. While prior research suggests that interventions can be successful when they provide behavioral directions (Okhuysen \& Eisenhardt, 2002), the sheer breadth and depth of behavioral directions provided in this training may have been too extensive to be sufficiently actionable.

Fourth, it is possible that the low base rate of behaviors may have been responsible for the low endorsement of behaviors. Although leaders in the training group were trained to engage in behaviors at least once per week, it is possible that once per week was not a high enough frequency to elicit employee recognition of leader behavior change (Bolger, Davis, \& Rafaeli, 2003). For instance, although leaders may have been communicating more frequently about mental health and suggesting more opportunities for problem-focused coping, they may not have been doing so frequently enough to prompt employees to perceive their behavior differently. Similarly, it is possible that some leaders provided behavioral support so expertly than their behaviors were not recognized by employees. According to politeness theory, some people are able to provide "invisible support" in such a way that does not draw attention to the individual's need for support (Brown \& Levinson, 1987), and that effective support sometimes occurs so seamlessly that it goes unrecognized by the recipient (Lieberman, 1986). Given 
employees' high perceptions of leader support and low endorsement of leaders' actual support behaviors, this explanation may be appropriate.

Regardless of the potential explanation, the lack of impact of the training on supervisors' support behaviors likely influenced the lack of impact the training had on all outcome variables. According to the resource utilization model (RUM; Dimoff et al., 2016), we expected improvements in supervisor support to initiate a larger training transfer process. As depicted in Figure 1, we anticipated that the training would 1) lead to increases in supervisor support and improvements in supervisor supportive behaviors, and 2) employee recognition of more frequent supervisor supportive behaviors. Ultimately, these changes would impact employee well-being (i.e., burnout), as well as employee attitudes and behaviors related to seeking support (i.e., problem-focused coping, turnover intentions, and attendance). Based on this expected process, a failure in the first step would result in failure in all subsequent steps. Given that employees did not perceive a significant improvement in supervisors' support or supportive behaviors, it is unsurprising that no subsequent impacts of the training were observed.

The lack of significant results in this study could also be the result of a lack of training transfer (i.e., the implementation of learned skills on the job; Burke \& Hutchins, 2007), as well as inadequate attention to job characteristics (Holman \& Axtell, 2016). Skills transfer is a significant problem for training programs, in that $40 \%$ of trainees do not transfer skills immediately after training and $70 \%$ do not implement skills up to one 
year after training (Saks, 2002). Moreover, only 50\% of training interventions result in improvements to organization or individual outcomes (Saks, 2002).

Burke and Hutchins (2007) identified drivers that impact training transfer, including work environment characteristics and intervention design and delivery in their review of research on training transfer. The call center environment is potentially inconducive to supervisor mental health training transfer because of competing priorities. Past research has found that training transfer is bolstered by an alignment between strategic objectives, department goals, and the content of the training (Burke \& Hutchins, 2007). Senior leaders' endorsement for mental health training may not be enough to facilitate the transfer of supervisor skills into a call center, where performance goals are based on call handling metrics.

The intervention design consisted of one three-hour training session for supervisors. Attendees received training materials which included the signs of struggle scale (Dimoff \& Kelloway, 2018) and other resources, in a one-page format designed to be hung in the supervisors workspace for easy reference when interacting with employees. This was consistent with previous MHAT interventions (Dimoff \& Kelloway, 2019), which did not include follow-up or booster sessions to facilitate training transfer. Several effective interventions have utilized coaching, feedback, follow up activities, and booster sessions (e.g. Hammer et al., 2019). Kelloway and Barling (2010) note that intervention intensity (i.e., the strength of dose) is an important design consideration but that there is considerable variation across effective interventions. It may be that training 
transfer requires different levels of follow-up, perhaps based on industry or company characteristics. For example, supervisors in call center environments where there are high levels of task variety may need a more intense intervention design to translate skills into practice.

Specific objectives and goals related to employee mental health may be needed to motivate supervisors to enact the supportive behaviors taught in the training. Moreover, greater attention may have to be given to changing the job characteristics in call centers if organizations hope to see reductions in burnout, absenteeism, and turnover (Deery et al., 2002). Thus, the non-significant findings of this study may also be related to a mismatch between the training content and the job design of most call center employees. Existing research findings suggest that call center employees were significantly more likely to become emotionally exhausted (a key component of burnout) when they felt customers had become more abusive (Deery et al., 2002). Under the buffering hypothesis of social support (Viswesvaran et al., 1999), it may be that role stressors from other sources, such as abusive customers, were greater than the mitigating effects of high levels of perceived supervisor support. As a result, I would not expect to see a reduction in burnout, withdrawal behaviors, or turnover intentions simply because we provided a leadership training related to mental health. Deery and colleagues (2002) found that supervisor support on job-related tasks in call centers was associated with reduced emotional exhaustion. Supervisor support of non-job tasks (i.e., mental well-being and developing coping strategies) was the target of this study, and may explain why this intervention 
study didn't replicate the employee-level outcomes of previous MHAT research (Dimoff \& Kelloway, 2019).

Call center environments are metric-driven organizations, often focused on delivering a standardized level of service in mass quantity through prescribed, routinized, and monitored oversight (Houlihan, 2001). Front-line call center employees typically have little control, autonomy, and decision-making authority in executing the functions of the role (Jack, Bedics, \& McCary, 2006), with high priority placed on very specific metrics, such as call volume, time between calls, number of call transfers, and customer satisfaction ratings. High turnover rates and pressure from leadership to drive down costs can lead to unique challenges that may impact findings of this study, as compared to other industries (Houlihan, 2001). For example, supervisors may not recognize when their employees are struggling due to a preoccupation with achieving performance metrics. Likewise, high levels of turnover may result in a supervisor's failure to recognize struggle in an employee who recently joined the team.

Call center organizations often track employee time closely, given the highlymonitored nature of the role and that absenteeism in call centers can result in insufficient staffing to meet customer service demands (Rauhala et al., 2007). Twelve consecutive months of objective attendance performance data were provided by the organization; however, there were no significant differences in the number of hours attributed to withdrawal behavior attendance codes between the intervention and control groups in the three months after the study began. These results are not surprising based on the 
nonsignificant findings in the upstream outcome variables (i.e., problem-focused coping and burnout) because I hypothesized that attendance would improve as a result of more adaptive coping and lower burnout. Another potential explanation for this result is inconsistent use of codes across teams. There were established company guidelines for the use of various attendance codes; however, the attendance management tracking system relies on the employee and supervisor to enter and approve the hours in the appropriate classification. As a result, the group-level attendance data may be unreliable measures of attendance behaviors of individuals.

Although not central to the specific hypotheses and goals of this study, I also proposed three research questions with the goal of better understanding the relationship between predictor and outcome variables through potential explanatory processes (i.e., mediators). Unfortunately, the non-significant nature of the findings related to these research questions do not provide insight into to process of change, in large part due to the lack of significant findings related to the central hypotheses. Had findings been significant, these research questions may have provided important insight into the process of change related to employee withdrawal intentions (i.e., turnover and absenteeism intentions).

\section{Limitations \& Future Directions}

This study has several limitations that warrant further exploration to better understand the mechanisms by which supervisor mental health training can successfully improve employee attitudes, behaviors, and well-being outcomes. The major limitations 
of this study include a small and underpowered sample size, a lack of generalizability, and methodological limitations.

The final sample size $(N=74)$ did not provide sufficient power to detect moderate training effects, based on the power analysis conducted for this study. At least 128 participants were needed to detect an effect size of .25. MI analysis was conducted in an effort to evaluate whether attrition factored into the non-significant results. While MI did not produce different outcomes in this sample, future research with larger organizations, or those with fewer time constraints on participants, may result in higher participation rates and sufficient power to test effects. A larger sample size in future studies also may enable the testing of mediation through more complex modeling and path analysis.

This study involved a unique sample that may not be generalizable to other workplaces. First, the call center industry is highly-monitored, metrics-driven, and may not be representative of other industries. Second, this sample contained an uncharacteristically large percentage of individuals who self-identified as LGBT (39.2\% across groups). It is estimated that $4.5 \%$ of the adult population in the United States identifies as LGBT (Newport, 2018). Marginalized populations, such as this one, are more likely to experience higher levels of strain and negative outcomes such as burnout and turnover intentions than non-LGBT-identifying individuals (Meyer, 2003; Miller \& Major, 2000). As a result, this sample may not be characteristic of other workplace samples. Future research should be mindful to develop and evaluate interventions specifically designed to support marginalized populations within the workforce. 
This study had some methodological limitations. The first was the short duration of the study. There was only one post-training assessment survey, which was administered six weeks after the intervention. This design was selected to reduce disruption to organizational operations and because of the higher-than-average turnover rates in this particular organization. It is likely that the attrition rate would have been even higher if the study was conducted over a longer timeframe due to participants leaving the organization. Similar studies have evaluated supervisor and employee intervention outcomes at more than two time points over a six to nine month timeframe (Dimoff \& Kelloway, 2019; Hammer et al., 2019). The data in this sample was nested (i.e., employees nested within supervisors), which may have been an issue affecting the interpretation of findings. Future research should take this into consideration when evaluating effects of supervisor training on employees. Future research should also explore the impacts of supervisor training on employee outcomes at additional time points and over a longer period of time. Longer-term studies may provide valuable insights into a) better understanding of the process of change over time, b) effects on objective business metrics such as turnover (as opposed to intentions to turnover), and c) the lasting impacts of supervisor training on employee coping and engagement behaviors. The supervisor support measures used in this study represent another methodological limitation. The perceived supervisor support scale was an adaptation of the Survey of Perceived Organizational Support (SPOS; Eisenberger et al., 1986); the use and adaptation of this scale was consistent with previous research (e.g., DeConinck, 
2010; Rhoades et al., 2001). However, a different supervisor support scale that mapped onto the relevant facets of social support (i.e., emotional, instrumental, informational, and appraisal support) may have provided greater insights into the manner by which employees felt supported by their supervisors. Additionally, the scale used to measure supervisors' supportive behaviors was based on an unvalidated scale used in previous MHAT research (Dimoff et al., 2016; Dimoff \& Kelloway, 2019), and was adapted to identify the specific behaviors trained in this intervention. These behaviors may not be the only supportive supervisor behaviors recognized by the employees. Therefore, future research should carefully consider the supervisor support measures selected and develop a validated scale for mental health supportive supervisor behaviors.

Finally, this study evaluated a lecture-based supervisor intervention, which is just one of several workplace intervention formats (Richardson \& Rothstein, 2008). As discussed previously, the lecture-based format may not be appropriate for call center organizations because of the conflicting and metric-focused job demands on the supervisor role. Online, self-paced training or individual coaching are more effective in facilitating training transfer from the intervention into practice. Future research could evaluate these different intervention approaches and modalities within a call center environment.

\section{Conclusion}

Organizations rely on their call center employees to serve as the crucial intermediary between the customer and the company. Yet, the typical call center role 
requires emotional labor (e.g., surface and/or deep acting), repetitive and monotonous tasks, close supervision, and little autonomy. Supervisors and management are continuously working to combat burnout, absenteeism, and turnover. The present study aimed to evaluate a supervisor mental health training intervention as a company-provided external resource, within the job demands-resources model, to improve employee attitudes, behaviors, and well-being outcomes. While the intervention was not effective in improving employee attitudes and behaviors up to six weeks after the supervisor training, due in part to the short study duration, lack of training transfer, and the ceiling effect on supervisor support variable, supervisor-focused interventions may still unlock resource savings (e.g., costs and training resources) for the organization and improved mental well-being and job satisfaction for call center employees. 
Tables

Table 1

Employee demographics

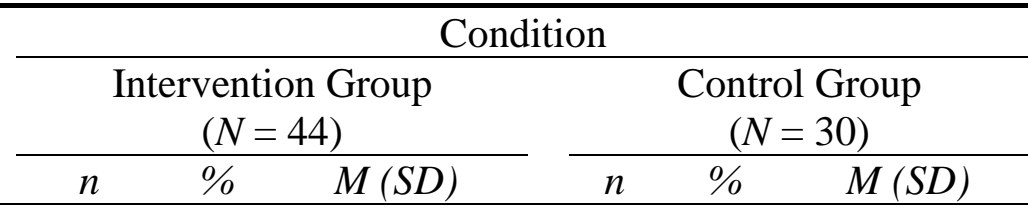

\begin{tabular}{|c|c|c|c|c|c|c|}
\hline \multirow{2}{*}{\multicolumn{7}{|c|}{$\begin{array}{l}\text { Age } \\
\text { Gender }\end{array}$}} \\
\hline & & & & & & \\
\hline Male & 9 & 20.5 & & 3 & 10.0 & \\
\hline Female & 30 & 68.2 & & 24 & 80.0 & \\
\hline Non-binary & 4 & 9.1 & & 0 & 0.0 & \\
\hline Prefer not to say & 1 & 2.3 & & 3 & 10.0 & \\
\hline \multicolumn{7}{|l|}{ LGBT } \\
\hline Yes & 20 & 45.5 & & 9 & 30.0 & \\
\hline No & 3 & 6.8 & & 6 & 20.0 & \\
\hline No, ally & 19 & 43.2 & & 13 & 43.3 & \\
\hline Prefer not to say & 2 & 4.5 & & 2 & 6.7 & \\
\hline Tenure (months) & & & $14.67(10.08)$ & & & $19.40(21.17)$ \\
\hline Interaction with manager & & & $1.48(0.73)$ & & & $1.60(0.62)$ \\
\hline \multicolumn{7}{|l|}{ Mental health experience } \\
\hline Yes & 42 & 95.5 & & 29 & 96.7 & \\
\hline No & 2 & 4.5 & & 1 & 3.3 & \\
\hline
\end{tabular}


Table 2.a

Correlations between the employee variables (intervention group)

\begin{tabular}{|c|c|c|c|c|c|c|c|c|c|c|}
\hline Variables & $M(S D)$ & 1 & 2 & 3 & 4 & 5 & 6 & 7 & 8 & 9 \\
\hline 1.Gender & - & - & & & & & & & & \\
\hline 2. LGBT & - & .007 & - & & & & & & & \\
\hline 3. Age & $30.51(6.24)$ & -.018 & -.048 & - & & & & & & \\
\hline 4. Tenure (months) & $14.67(10.08)$ & -.225 & .069 & .174 & - & & & & & \\
\hline 5. Interaction & $1.48(0.73)$ & .124 & -.166 & -.190 & -.134 & - & & & & \\
\hline 6. Supervisor Support-T1 & $5.59(.59)$ & -.116 & -.153 & .153 & .213 & -.137 & $(.883)$ & & & \\
\hline 7. Supervisor Support-T2 & $5.34(.78)$ & -.137 & .064 & $.320^{*}$ & $.320^{*}$ & -.107 & $.694^{* *}$ & (.895) & & \\
\hline 8. Support Behavior-T1 & $5.04(.75)$ & -.211 & .033 & .235 & $.341^{*}$ & -.236 & $.707^{* *}$ & $.814^{* *}$ & $(.892)$ & \\
\hline 9. Support Behavior-T2 & $4.91(.90)$ & -.190 & .232 & .228 & $.392^{* *}$ & -.264 & $.659^{* *}$ & $.798^{* *}$ & $.860^{* *}$ & $(.932)$ \\
\hline 10. Burnout-T1 & $3.09(.99)$ & -.039 & -.166 & $-.408^{* *}$ & .067 & .235 & $-.399^{* *}$ & $-.614^{* *}$ & $-.498^{* *}$ & $-.570^{* *}$ \\
\hline 11. Burnout-T2 & $3.37(1.09)$ & -.003 & -.083 & $-.360^{*}$ & .046 & $.302^{*}$ & -.276 & $-.494^{* *}$ & $-.331^{*}$ & $-.478^{* *}$ \\
\hline 12. Prob-focused coping-T1 & $3.16(.64)$ & $.304^{*}$ & -.072 & .034 & .055 & .221 & -.070 & .092 & -.088 & .027 \\
\hline 13. Prob-focused coping-T2 & $3.11(.59)$ & .180 & .002 & .118 & .036 & -.159 & .214 & .210 & .085 & .283 \\
\hline 14. Turnover-T1 & $2.89(1.78)$ & -.205 & -.136 & -.194 & .132 & $.325^{*}$ & -.238 & -.284 & -.265 & $-.324^{*}$ \\
\hline 15. Turnover-T2 & $3.53(1.92)$ & -.067 & -.064 & -.249 & .004 & $.319^{*}$ & -.244 & $-.346^{*}$ & $-.309^{*}$ & $-.384^{*}$ \\
\hline
\end{tabular}


Table 2.b

Correlations between employee variables (intervention group), cont. from Table 2.a

\begin{tabular}{lrrrrrr}
\hline \multicolumn{1}{c}{ Variables } & \multicolumn{1}{c}{10} & & & \\
& 10 & 11 & 12 & 13 & 14 & 15 \\
\hline 10. Burnout-T1 & $\mathbf{( . 9 3 0 )}$ & & & & & \\
11. Burnout-T2 & $.818^{* *}$ & $\mathbf{( . 9 5 4 )}$ & & & & \\
12. Prob-focused coping-T1 & $-.307^{*}$ & -.272 & $\mathbf{( . 8 4 2 )}$ & & & \\
13. Prob-focused coping-T2 & $.465^{* *}$ & $-.537^{* *}$ & $.575^{* *}$ & $\mathbf{( . 8 6 0 )}$ & & \\
14. Turnover-T1 & $.701^{* *}$ & $.636^{* *}$ & -.294 & $-.595^{* *}$ & $\mathbf{( . 9 3 3 )}$ & \\
15. Turnover-T2 & $.680^{* *}$ & $.787^{* *}$ & $-.341^{*}$ & $-.531^{* *}$ & $.828^{* *}$ & $\mathbf{( . 9 6 7 )}$ \\
& & & & & & \\
\hline
\end{tabular}

Note. Cronbach's alpha $(\alpha)$ scores are shown in parentheses on the diagonal; T1 = Time 1 , baseline; T2 = Time 2, 6 week follow-up; $* \mathrm{p}<.05 ; * * \mathrm{p}<.01$ 
Table 3.a

Correlations between the employee variables (control group)

\begin{tabular}{|c|c|c|c|c|c|c|c|c|c|c|}
\hline Variables & $M(S D)$ & 1 & 2 & 3 & 4 & 5 & 6 & 7 & 8 & 9 \\
\hline 1. Gender & - & - & & & & & & & & \\
\hline 2. LGBT & - & .109 & - & & & & & & & \\
\hline 3. Age & $32.03(6.54)$ & -.104 & .079 & - & & & & & & \\
\hline 4. Tenure Months & $19.40(21.17)$ & .204 & .357 & $.597^{* *}$ & - & & & & & \\
\hline 5. Interaction & $1.60(0.62)$ & .171 & -.045 & -.132 & .079 & - & & & & \\
\hline 6. Supervisor Support-T1 & $5.32(.74)$ & $-.423 *$ & .207 & .023 & -.025 & $-.633^{* *}$ & $(.915)$ & & & \\
\hline 7. Supervisor Support-T2 & $5.05(1.02)$ & -.325 & .191 & .179 & .068 & $-.595^{* *}$ & $.745^{* *}$ & $(.946)$ & & \\
\hline 8. Supervisor Behavior-T1 & $4.77(.88)$ & $-.363^{*}$ & .079 & .267 & .132 & $-.742^{* *}$ & $.753^{* *}$ & $.763^{* *}$ & $(.907)$ & \\
\hline 9. Supervisor Behavior-T2 & $4.51(1.09)$ & -.285 & .275 & .255 & .217 & $-.592^{* *}$ & $.630^{* *}$ & $.848^{* *}$ & $.827^{* *}$ & $(.953)$ \\
\hline 10. Burnout-T1 & $3.00(1.04)$ & $.436^{*}$ & .052 & -.270 & .126 & .369 & $-.597^{* *}$ & $-.584^{* *}$ & $-.644^{* *}$ & $-.589^{* *}$ \\
\hline 11. Burnout-T2 & $3.15(1.15)$ & $.403^{*}$ & -.144 & -.348 & -.152 & $.462^{*}$ & $-.627^{* *}$ & $-.654^{* *}$ & $-.710^{* *}$ & $-.709^{* *}$ \\
\hline 12. Prob-focused coping-T1 & $3.12(.61)$ & -.090 & .074 & .072 & .017 & $-.406^{*}$ & $.403^{*}$ & .366 & $.478^{* *}$ & .216 \\
\hline 13. Prob-focused coping-T2 & $2.99(.62)$ & -.056 & .112 & .222 & .033 & -.367 & .138 & .335 & $.490^{* *}$ & $.446^{*}$ \\
\hline 14. Turnover-T1 & $2.07(1.48)$ & $.426^{*}$ & .046 & -.263 & .035 & $.415^{*}$ & $-.526^{* *}$ & $-.486^{* *}$ & $-.482^{* *}$ & $-.472^{* *}$ \\
\hline 15. Turnover-T2 & $2.46(1.77)$ & $.390^{*}$ & -.143 & -.276 & -.190 & $.542^{* *}$ & $-.578^{* *}$ & $-.694^{* *}$ & $-.682^{* *}$ & $-.636^{*}$ \\
\hline
\end{tabular}


Table 3.b

Correlations between employee variables (control group), cont. from Table 3.a

\begin{tabular}{lcrrrrr}
\multicolumn{1}{c}{ Variables } & 10 & 11 & 12 & 13 & 14 & 15 \\
\hline 10. Burnout-T1 & $\mathbf{( . 9 4 5 )}$ & & & & & \\
11. Burnout-T2 & $.870^{* *}$ & $\mathbf{( . 9 4 0 )}$ & & & & \\
12. Prob-focused coping-T1 & -.349 & $-.421^{*}$ & $\mathbf{( . 8 5 1 )}$ & & & \\
13. Prob-focused coping-T2 & $-.517^{* *}$ & $-.594^{* *}$ & $-.421^{*}$ & $\mathbf{( . 8 8 4 )}$ & & \\
14. Turnover-T1 & $.761^{* *}$ & $.751^{* *}$ & -.163 & $-.390^{*}$ & $\mathbf{( . 9 3 2 )}$ & \\
15. Turnover-T2 & $.681^{* *}$ & $.837^{* *}$ & -.313 & $-.510^{* *}$ & $.761^{* *}$ & $\mathbf{( . 9 7 9 )}$
\end{tabular}

Note. Cronbach's alpha $(\alpha)$ scores are shown in parentheses on the diagonal; T1 = Time 1, baseline;

T2 = Time 2, 6 week follow-up; *p $<.05 ; * * p<.01$ 
Table 4

Univariate effects for repeated measures MANOVA

\begin{tabular}{|c|c|c|c|c|c|c|}
\hline \multirow[b]{2}{*}{ Variable } & \multicolumn{2}{|c|}{$\begin{array}{c}\text { Intervention Group } \\
\text { Mean (SD) } \\
\end{array}$} & \multicolumn{2}{|c|}{$\begin{array}{c}\text { Control Group } \\
\text { Mean (SD) }\end{array}$} & \multirow[b]{2}{*}{$F$} & \multirow[b]{2}{*}{$\eta^{2}$} \\
\hline & Time 1 & Time 2 & Time 1 & Time 2 & & \\
\hline Supervisor Support & $5.59(.59)$ & $5.34(.78)$ & $5.32(.73)$ & $5.05(1.02)$ & .054 & .001 \\
\hline Support Behaviors & $5.05(.75)$ & $4.91(.90)$ & $4.77(.88)$ & $4.51(.09)$ & .993 & .014 \\
\hline Burnout & $3.08(.99)$ & $3.37(1.08)$ & $3.00(1.04)$ & $3.15(1.15)$ & .725 & .011 \\
\hline Turnover Intentions & $2.89(1.78)$ & $3.53(1.92)$ & $2.07(1.48)$ & $2.46(1.77)$ & .886 & .013 \\
\hline Problem-focused coping & $3.15(.64)$ & $3.11(.59)$ & $3.12(.62)$ & $2.99(.62)$ & .330 & .005 \\
\hline
\end{tabular}

Note: All F's with 1, 68 degrees of freedom. ${ }^{*} \mathrm{p}<.05$ 
Table 5

Research Question 1: Growth Curve Analyses

\begin{tabular}{lccc}
\hline & Estimate & SE & $p$ \\
\hline $\begin{array}{l}\text { Turnover Intentions }(n=460) \\
\quad \text { Fixed Effects }\end{array}$ & & & \\
$\quad$ Intercept & 2.27 & 0.21 & $0.000^{* * *}$ \\
$\quad$ Time & 0.02 & 0.05 & 0.750 \\
& & & \\
Random Effects & & & \\
$\quad$ Intercept variance^ & 4.09 & 0.82 & $0.000^{* * *}$ \\
$\quad$ Intercept slope covariance & -0.61 & 0.19 & $0.002^{* *}$ \\
$\quad$ Slope variance & 0.14 & 0.05 & $0.008^{* *}$
\end{tabular}

Absent Intentions $(n=523)$

Fixed Effects

$\begin{array}{lccc}\text { Intercept } & 3.70 & 0.18 & 0.000 * * * \\ \text { Time } & 0.03 & 0.04 & 0.549\end{array}$

Random Effects

Intercept variance ${ }^{\wedge}$

$\begin{array}{lll}3.55 & 0.67 & 0.000 * * *\end{array}$

Intercept slope covariance

$\begin{array}{lll}-0.57 & 0.15 & 0.000 * * *\end{array}$

Slope variance ${ }^{\wedge}$

$\begin{array}{lll}0.14 & 0.04 & 0.000 * * *\end{array}$

$\wedge$ Intercept and slope variance $\mathrm{p}$-values based on one-tailed significance test.

$* * p<.01, * * * p<.001$ 
Table 6

Research Question 2: Growth Curve Analyses

\begin{tabular}{lccc}
\hline & Estimate & SE & $p$ \\
\hline Supportive behaviors and turnover intentions $(n=330)$ & & \\
Fixed Effects & & & \\
$\quad$ Intercept & 2.25 & 0.22 & $0.000^{* * *}$ \\
Supportive behaviors & 0.32 & 0.55 & 0.56 \\
Time & 0.04 & 0.05 & -0.06 \\
Supportive behaviors*Time & 0.15 & 0.13 & -0.11 \\
& & & \\
Random Effects & & & \\
Intercept variance^ & 3.80 & 0.72 & $0.000^{* * *}$ \\
Intercept slope covariance & -0.43 & 0.14 & $0.002^{* *}$ \\
Slope variance & 0.10 & 0.04 & $0.004 * *$
\end{tabular}

Coping and turnover intentions $(n=324)$

Fixed Effects

$\begin{array}{lccc}\text { Intercept } & 2.21 & 0.22 & 0.000 * * * \\ \text { Problem-focused coping } & 0.15 & 0.17 & 0.37 \\ \text { Time } & 0.05 & 0.99 & 0.33 \\ \text { Problem-focused coping*Time } & 0.01 & 0.15 & 0.87\end{array}$

Random Effects

$\begin{array}{lccc}\text { Intercept variance } & 3.67 & 0.70 & 0.000 * * * \\ \text { Intercept slope covariance } & -0.42 & 0.14 & 0.002 * * \\ \text { Slope variance }^{\wedge} & 0.11 & 0.04 & 0.003 * *\end{array}$

Supportive behaviors and absent intentions $(n=360)$

Fixed Effects

$\begin{array}{lccc}\text { Intercept } & 3.68 & 0.20 & 0.000 * * * \\ \text { Supportive behaviors } & 0.06 & 0.53 & 0.91 \\ \text { Time } & 0.05 & 0.05 & 0.33 \\ \text { Supportive behaviors*Time } & 0.34 & 0.17 & 0.05\end{array}$

Random Effects
Intercept variance ${ }^{\wedge}$
3.05
0.58
$0.000 * * *$ 
Table 6, cont.

Research Question 2: Growth Curve Analyses

\begin{tabular}{lccc}
\hline & Estimate & SE & $p$ \\
\hline Intercept slope covariance & -0.47 & 0.12 & $0.000^{* * *}$ \\
$\quad$ Slope variance & 0.12 & 0.03 & $0.000^{\wedge * *}$ \\
Coping and absent intentions $(n=353)$ & & & \\
$\quad$ Fixed Effects & & & \\
$\quad$ Intercept & 3.63 & 0.19 & $0.000^{* * *}$ \\
Coping & 0.45 & 0.17 & $0.01 * *$ \\
Time & 0.06 & 0.05 & 0.28 \\
Coping*Time & -0.05 & 0.05 & 0.28 \\
& & & \\
Random Effects & & & \\
Intercept variance & & & \\
Intercept slope covariance & 2.683 & 0.53 & $0.000^{* * *}$ \\
Slope variance & -0.41 & 0.12 & $0.001 * * *$ \\
& 0.12 & 0.04 & $0.000^{* * *}$ \\
\hline
\end{tabular}

Note: Supportive behaviors and coping variables centered; coping = problem-focused coping.

${ }^{\wedge}$ Intercept and slope variance $\mathrm{p}$-values based on one-tailed significance test.

$* * p<.01, * * * p<.001$ 
Research Question 3: Growth Curve Analyses

\begin{tabular}{|c|c|c|c|}
\hline & Estimate & SE & $p$ \\
\hline \multicolumn{4}{|c|}{ Three-way interaction on absent intentions $(n=353)$} \\
\hline \multicolumn{4}{|c|}{ Fixed Effects } \\
\hline Intercept & 3.61 & 0.20 & $0.000 * * *$ \\
\hline Supportive behaviors & 0.53 & 0.39 & 0.18 \\
\hline Coping & 0.40 & 0.17 & $0.03 *$ \\
\hline Time & 0.08 & 0.05 & 0.10 \\
\hline Supportive behaviors*Coping & 0.20 & 0.58 & 0.73 \\
\hline Coping*Time & -0.05 & 0.05 & 0.33 \\
\hline Supportive behaviors*Coping*Time & -0.21 & 0.17 & 0.22 \\
\hline \multicolumn{4}{|l|}{ Random Effects } \\
\hline Intercept variance & 2.83 & 0.56 & $0.000 * * *$ \\
\hline Intercept slope covariance & -0.43 & 0.12 & $0.000 * * *$ \\
\hline Slope variance & 0.12 & 0.03 & $0.000 * * *$ \\
\hline \multicolumn{4}{|c|}{ Three-way interaction on turnover intentions $(n=324)$} \\
\hline \multicolumn{4}{|l|}{ Fixed Effects } \\
\hline Intercept & 2.23 & 0.24 & $0.000 * * *$ \\
\hline Supportive behaviors & 0.33 & 0.5 & 0.50 \\
\hline Coping & 0.14 & 0.18 & 0.46 \\
\hline Time & 0.07 & 0.05 & 0.22 \\
\hline Supportive behaviors*Coping & 0.01 & 0.05 & 0.85 \\
\hline Coping*Time & -0.14 & 0.47 & 0.77 \\
\hline Supportive behaviors*Coping*Time & -0.11 & 0.11 & 0.33 \\
\hline \multicolumn{4}{|l|}{ Random Effects } \\
\hline Intercept variance $^{\wedge}$ & 3.74 & 0.71 & $0.000 * * *$ \\
\hline Intercept slope covariance & -0.43 & 0.14 & $0.002 * *$ \\
\hline Slope variance ${ }^{\wedge}$ & 0.10 & 0.04 & $0.003 * *$ \\
\hline
\end{tabular}

Note: Supportive behaviors and coping variables centered; coping = problem-focused coping.

${ }^{\wedge}$ Intercept and slope variance p-values based on one-tailed significance test.

$* p<0.05, * * p<.01, * * * p<.001$ 
Table 8

Attrition Analyses

\begin{tabular}{|c|c|c|c|}
\hline & $\begin{array}{c}\mathrm{T} 2 \\
\text { Completed } \\
(N=102)\end{array}$ & $\begin{array}{c}\text { T2 Not } \\
\text { Complete } \\
(N=109)\end{array}$ & $p^{a}$ \\
\hline Condition & & & $0.01 * *$ \\
\hline Intervention & $61(60)$ & $46(42)$ & \\
\hline Control & $41(40)$ & $63(58)$ & \\
\hline Age & $30.63(6.43)$ & $28.86(6.88)$ & 0.10 \\
\hline Gender & & & 0.50 \\
\hline Male & $12(16)$ & $18(23)$ & \\
\hline Female & $57(74)$ & $53(67)$ & \\
\hline Non-binary & $4(5)$ & $2(3)$ & \\
\hline Prefer not to say & $4(5)$ & $6(8)$ & \\
\hline LGBT & & & 0.08 \\
\hline Yes & $29(38)$ & $32(41)$ & \\
\hline No & $10(13)$ & $21(27)$ & \\
\hline No, ally & $34(44)$ & $22(28)$ & \\
\hline Prefer not to say & $4(5)$ & $2(4)$ & \\
\hline Supervisor Support & $5.51(0.64)$ & $5.38(0.74)$ & 0.23 \\
\hline Supportive Behaviors & $4.94(0.83)$ & $4.94(0.91)$ & 0.99 \\
\hline Burnout & $3.06(1.00)$ & $3.29(1.05)$ & 0.16 \\
\hline Turnover Intentions & $2.55(1.71)$ & $2.85(1.76)$ & 0.28 \\
\hline
\end{tabular}

${ }^{a}$ Treatment condition, gender, and LGBT comparisons utilize chisquare analyses, all others utilize independent t-tests; $* * p<.01$ 
Table 9

Testing Treatment Differences on Outcomes at T2

\begin{tabular}{lccc}
\hline & $B$ & SE $B$ & $p$ \\
& & & \\
& & 0.10 & $0.00 * * *$ \\
Supervisor Support & 5.04 & 0.14 & 0.13 \\
$\quad$ Intercept & 0.21 & & \\
$\quad$ Intervention & & 0.12 & $0.00 * * *$ \\
Supportive Behaviors & 4.59 & 0.16 & 0.14 \\
$\quad$ Intercept & 0.23 & & $0.00 * * *$ \\
$\quad$ Intervention & & 0.10 & 0.63 \\
Problem-focused Coping & 2.97 & & \\
$\quad$ Intercept & 0.06 & 0.14 & $0.00 * * *$ \\
$\quad$ Intervention & 3.38 & 0.19 & 0.87 \\
Burnout & 0.03 & & \\
$\quad$ Intercept & & 0.24 & $0.00 * * *$ \\
$\quad$ Intervention & 3.04 & 0.31 & 0.45 \\
Turnover Intentions & 0.24 &
\end{tabular}


Figures

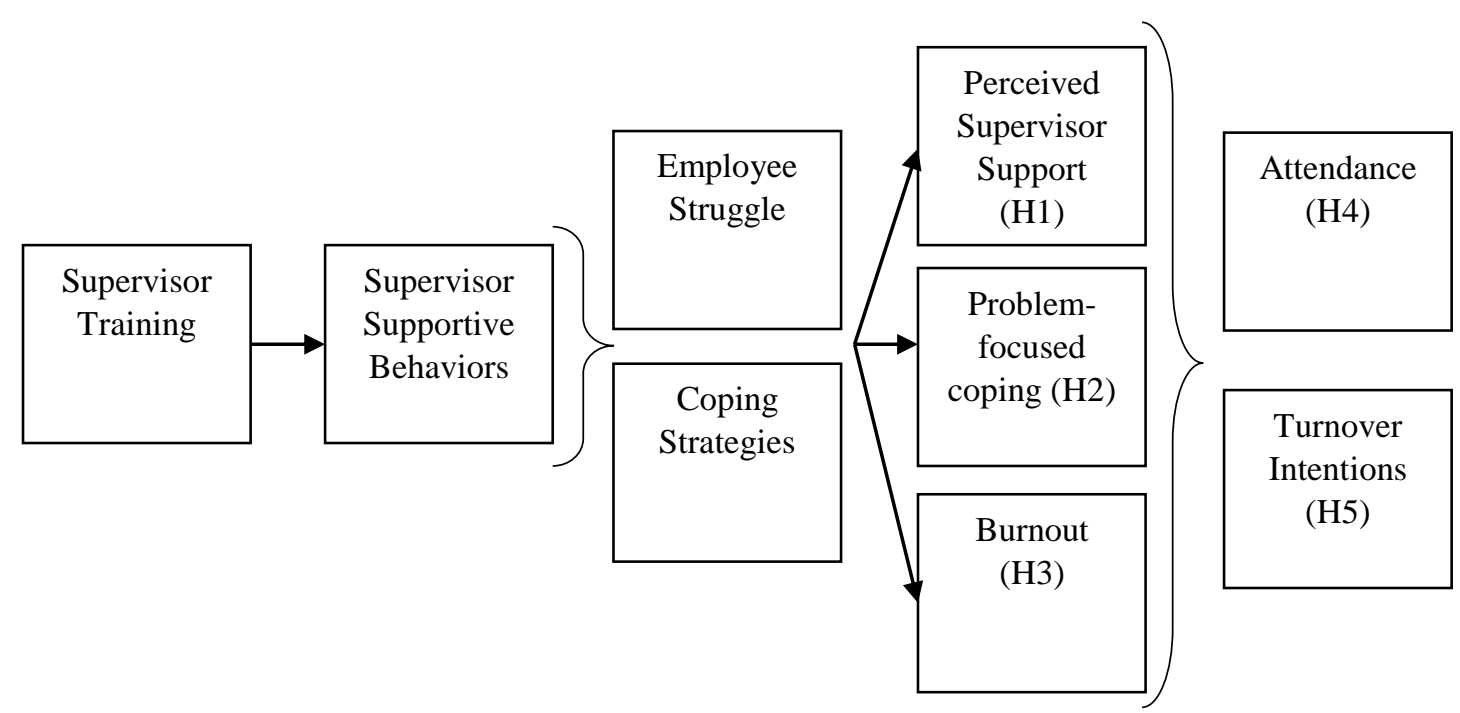

Figure 1. Hypothesized employee behaviors and outcomes. 


\begin{tabular}{|c|c|c|}
\hline \multirow{2}{*}{ Time } & & $\begin{array}{l}\text { Withdrawal } \\
\text { intentions }\end{array}$ \\
\cline { 2 - 3 } & (RQ1) \\
\hline
\end{tabular}
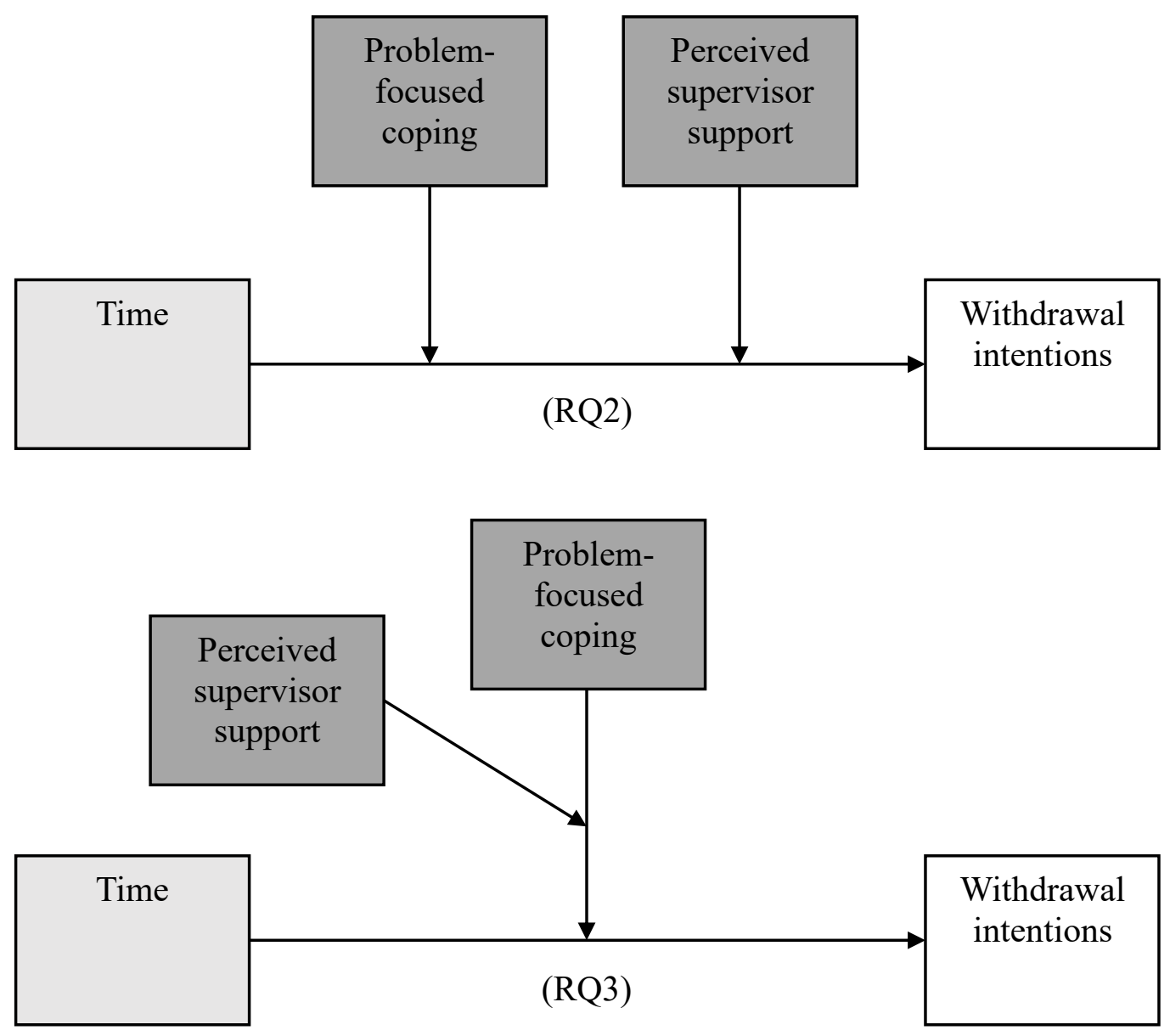

Figure 2. Hypothesized employee growth curve interactions. 
Intervention Group

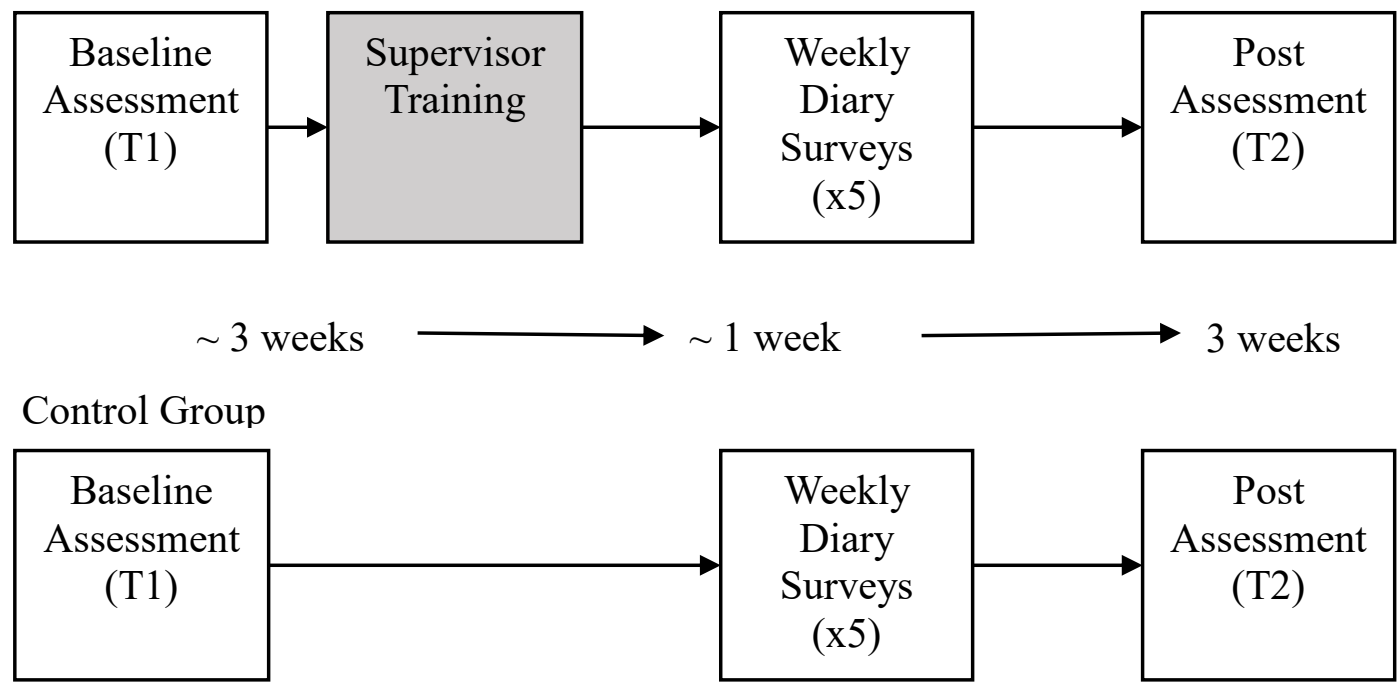

Figure 3. Intervention timeline. 


\section{References}

Ahola, K., Honkonen, T., Isometsä, E., Kalimo, R., Nykyri, E., Aromaa, A., \& Lönnqvist, J. (2005). The relationship between job-related burnout and depressive disorders - results from the Finnish Health 2000 Study. Journal of Affective Disorders, 88(1), 55-62. https://doi.org/10.1016/j.jad.2005.06.004

Allen, D. G., Weeks, K. P., \& Moffitt, K. R. (2005). Turnover intentions and voluntary turnover: The moderating roles of self-monitoring, locus of control, proactive personality, and risk aversion. Journal of Applied Psychology, 90(5), 980-990. http://dx.doi.org.proxy.lib.pdx.edu/10.1037/0021-9010.90.5.980

Anger, W. K., Elliot, D. L., Bodner, T., Olson, R., Rohlman, D. S., Truxillo, D. M., ... Montgomery, D. (2015). Effectiveness of total worker health interventions. Journal of Occupational Health Psychology, 20(2), 226-247.

http://dx.doi.org.proxy.lib.pdx.edu/10.1037/a0038340

Ashforth, B. E., \& Humphrey, R. H. (1993). Emotional labor in service roles: The influence of identity. The Academy of Management Review, 18(1), 88-115. https://doi.org/10.2307/258824

Attridge, M. (2009). Measuring and managing employee work engagement: A review of the research and business literature. Journal of Workplace Behavioral Health, 24(4), 383-398. https://doi.org/10.1080/15555240903188398 
Bagozzi, R. P., Yi, Y., \& Phillips, L. W. (1991). Assessing construct validity in organizational research. Administrative Science Quarterly, 36(3), 421-458. https://doi.org/10.2307/2393203

Bailey, J. J., \& McCollough, M. A. (2000). Emotional labor and the difficult customer: Coping strategies of service agents and organizational consequences. Journal of Professional Services Marketing, 20(2), 51-72. https://doi.org/10.1300/J090v20n02_05

Bakker, A. B., \& Demerouti, E. (2007). The job demands-resources model: State of the art. Journal of Managerial Psychology, 22(3), 309-328. https://doi.org/10.1108/02683940710733115

Bates, M. J., Bowles, S., Hammermeister, J., Stokes, C., Pinder, E., Moore, M., ... Rhodes, J. (2010). Psychological fitness. Military Medicine, 175(8S), 21-38.

Batt, R., \& Moynihan, L. (2002). The viability of alternative call centre production models. Human Resource Management Journal, 12(4), 14-34. https://doi.org/10.1111/j.1748-8583.2002.tb00075.x

Bolger, N., Davis, A., \& Rafaeli, E. (2003). Diary methods: Capturing life as it is lived. Annual Review of Psychology, 54(1), 579-616. https://doi.org/10.1146/annurev.psych.54.101601.145030

Bond, F. W., \& Bunce, D. (2000). Mediators of change in emotion-focused and problemfocused worksite stress management interventions. Journal of Occupational 
Health Psychology, 5(1), 156-163.

http://dx.doi.org.proxy.lib.pdx.edu/10.1037/1076-8998.5.1.156

Bowen, D. E., Siehl, C., \& Schneider, B. (1989). A framework for analyzing customer service orientations in manufacturing. The Academy of Management Review, 14(1), 75-95. https://doi.org/10.2307/258192

Brotheridge, C. M., \& Grandey, A. A. (2002). Emotional labor and burnout: Comparing two perspectives of “people work." Journal of Vocational Behavior, 60(1), 17-39. https://doi.org/10.1006/jvbe.2001.1815

Brown, P., \& Levinson, S. C. (1987). Politeness: Some universals in language usage. Cambridge University Press.

Burke, L. A., \& Hutchins, H. M. (2007). Training transfer: An integrative literature review. Human Resource Development Review, 6(3), 263-296. https://doi.org/10.1177/1534484307303035

Butterworth, S., Linden, A., McClay, W., \& Leo, M. C. (2006). Effect of motivational interviewing-based health coaching on employees' physical and mental health status. Journal of Occupational Health Psychology, 11(4), 358-365. http://dx.doi.org.proxy.lib.pdx.edu/10.1037/1076-8998.11.4.358

Carver, C. S. (1997). You want to measure coping but your protocol's too long: Consider the Brief COPE. International Journal of Behavioral Medicine, 4(1), 92. https://doi.org/10.1207/s15327558ijbm0401_6 
Carver, C. S., Scheier, M. F., \& Weintraub, J. K. (1989). Assessing coping strategies: A theoretically based approach. Journal of Personality and Social Psychology, 56(2), 267-283. http://dx.doi.org.proxy.lib.pdx.edu/10.1037/0022-3514.56.2.267

Cohen, S. (2004). Social relationships and health. American Psychologist, 59(8), 676684. http://dx.doi.org.proxy.lib.pdx.edu/10.1037/0003-066X.59.8.676

Cohen, S., \& Wills, T. A. (1985). Stress, social support, and the buffering hypothesis. Psychological Bulletin, 98(2), 310-357. http://dx.doi.org.proxy.lib.pdx.edu/10.1037/0033-2909.98.2.310

ContactBabel. (2016). The 2016 US Contact Center Decision-Makers' Guide (9th edition). Retrieved February 22, 2018, from www.contactbabel.com website: http://www.contactbabel.com/pdfs/july16/The-2016-US-Contact-CenterDecision-Makers-Guide.pdf

Cooper, C. L., \& Cartwright, S. (1994). Healthy mind; healthy organization- A proactive approach to occupational stress. Human Relations, 47(4), 455-471. https://doi.org/10.1177/001872679404700405

Cordes, C. L., \& Dougherty, T. W. (1993). A review and an integration of research on job burnout. The Academy of Management Review, 18(4), 621-656. https://doi.org/10.2307/258593

de Jong, G. M., \& Emmelkamp, P. M. G. (2000). Implementing a stress management training: Comparative trainer effectiveness. Journal of Occupational Health 
Psychology, 5(2), 309-320. http://dx.doi.org.proxy.lib.pdx.edu/10.1037/10768998.5.2.309

DeConinck, J. B. (2010). The effect of organizational justice, perceived organizational support, and perceived supervisor support on marketing employees' level of trust. Journal of Business Research, 63(12), 1349-1355.

https://doi.org/10.1016/j.jbusres.2010.01.003

Deery, S., Iverson, R., \& Walsh, J. (2002). Work relationships in telephone call centres: Understanding emotional exhaustion and employee withdrawal. Journal of Management Studies, 39(4), 471-496. https://doi.org/10.1111/1467-6486.00300

Demerouti, E., Bakker, A. B., Nachreiner, F., \& Schaufeli, W. B. (2001). The job demands-resources model of burnout. Journal of Applied Psychology, 86(3), 499512. http://dx.doi.org/10.1037/0021-9010.86.3.499

Diefendorff, J. M., \& Gosserand, R. H. (2003). Understanding the emotional labor process: A control theory perspective. Journal of Organizational Behavior, 24(8), 945-959. https://doi.org/10.1002/job.230

Dimoff, J. K., \& Kelloway, E. K. (2013). Bridging the gap: Workplace mental health research in Canada. Canadian Psychology/Psychologie Canadienne, 54(4), 203 212. http://dx.doi.org/10.1037/a0034464 
Dimoff, J. K., \& Kelloway, E. K. (2018). Signs of struggle (SOS): The development and validation of a behavioural mental health checklist for the workplace. Work \& Stress, 1-19. https://doi.org/10.1080/02678373.2018.1503359

Dimoff, J. K., \& Kelloway, E. K. (2019). With a little help from my boss: The impact of workplace mental health training on leader behaviors and employee resource utilization. Journal of Occupational Health Psychology, 24(1), 4-19. https://doi.org/10.1037/ocp0000126

Dimoff, J. K., Kelloway, E. K., \& Burnstein, M. D. (2016). Mental health awareness training (MHAT): The development and evaluation of an intervention for workplace leaders. International Journal of Stress Management, 23(2), 167-189. https://doi.org/10.1037/a0039479

Dulewicz, V., \& Higgs, M. (2000). Emotional intelligence - A review and evaluation study. Journal of Managerial Psychology, 15(4), 341-372. https://doi.org/10.1108/02683940010330993

Einhorn, H. J., \& Hogarth, R. M. (1986). Decision making under ambiguity. The Journal of Business, 59(4), S225-S250. Retrieved from JSTOR.

Eisenberger, R., Huntington, R., Hutchison, S., \& Sowa, D. (1986). Perceived organizational support. Journal of Applied Psychology, 71(3), 500-507. http://dx.doi.org.proxy.lib.pdx.edu/10.1037/0021-9010.71.3.500 
Ellering, N. (2018, September 24). Best time to send email backed by 14 data-driven studies. Retrieved March 16, 2019, from CoSchedule Blog website: https://coschedule.com/blog/best-time-to-send-email/

Faul, F., Erdfelder, E., Lang, A.-G., \& Buchner, A. (2007). G*Power 3: A flexible statistical power analysis program for the social, behavioral, and biomedical sciences. Behavior Research Methods, 39(2), 175-191. https://doi.org/10.3758/BF03193146

Fisher, R. J. (1993). Social desirability bias and the validity of indirect questioning. Journal of Consumer Research, 20(2), 303-315.

Fritz, C., Ellis, A. M., Demsky, C. A., Lin, B. C., \& Guros, F. (2013). Embracing work breaks: Recovering from work stress. Organizational Dynamics, 42(4), 274-280. https://doi.org/10.1016/j.orgdyn.2013.07.005

Fritz, C., Lam, C. F., \& Spreitzer, G. M. (2011). It's the little things that matter: An examination of knowledge workers' energy management. Academy of Management Perspectives, 25(3), 28-39.

Grandey, A. A. (2000). Emotional regulation in the workplace: A new way to conceptualize emotional labor. Journal of Occupational Health Psychology, 5(1), 95-110. http://dx.doi.org/10.1037/1076-8998.5.1.95

Grandey, A. A. (2003). When "the show must go on": Surface acting and deep acting as determinants of emotional exhaustion and peer-rated service delivery. The 
Academy of Management Journal, 46(1), 86-96.

https://doi.org/10.2307/30040678

Grandey, A. A., Dickter, D. N., \& Sin, H.-P. (2004). The customer is not always right: Customer aggression and emotion regulation of service employees. Journal of Organizational Behavior, 25(3), 397-418. https://doi.org/10.1002/job.252

Hammer, L. B., Wan, W. H., Brockwood, K. J., Bodner, T., \& Mohr, C. D. (2019). Supervisor support training effects on veteran health and work outcomes in the civilian workplace. Journal of Applied Psychology, 104(1), 52-69. http://dx.doi.org.proxy.lib.pdx.edu/10.1037/ap10000354

Hobfoll, S. E. (1989). Conservation of resources: A new attempt at conceptualizing stress. American Psychologist, 44(3), 513-524. http://dx.doi.org.proxy.lib.pdx.edu/10.1037/0003-066X.44.3.513

Hobfoll, S. E. (2011). Conservation of resource caravans and engaged settings. Journal of Occupational and Organizational Psychology, 84(1), 116-122. https://doi.org/10.1111/j.2044-8325.2010.02016.x

Hochschild, A. R. (1983). The managed heart: Commercialization of human feeling. Retrieved from https://search-proquestcom.proxy.lib.pdx.edu/docview/60033630/980B6DA1AEE24E7DPQ/12 
Holdsworth, L., \& Cartwright, S. (2003). Empowerment, stress and satisfaction: An exploratory study of a call centre. Leadership \& Organization Development Journal, 24(3), 131-140. https://doi.org/10.1108/01437730310469552

Holman, D., \& Axtell, C. (2016). Can job redesign interventions influence a broad range of employee outcomes by changing multiple job characteristics? A quasiexperimental study. Journal of Occupational Health Psychology, 21(3), 284-295. http://dx.doi.org/10.1037/a0039962

Houlihan, M. (2001). Managing to manage? Stories from the call centre floor. Journal of European Industrial Training, 25(2/3/4), 208-220. https://doi.org/10.1108/03090590110395816

House, J. S. (1981). Work stress and social support. Reading, MA: Addison Wesley.

Hox, J. (2002). Multilevel analysis techniques and applications. Retrieved from https://search-proquestcom.proxy.lib.pdx.edu/docview/619721037/EBEDDB3027634034PQ/1

Jack, E. P., Bedics, T. A., \& McCary, C. E. (2006). Operational challenges in the call center industry: A case study and resource-based framework. Managing Service Quality: An International Journal, 16(5), 477-500.

https://doi.org/10.1108/09604520610686142 
Kelloway, E. K., \& Barling, J. (2010). Leadership development as an intervention in occupational health psychology. Work \& Stress, 24(3), 260-279. https://doi.org/10.1080/02678373.2010.518441

Kitchener, B. A., \& Jorm, A. F. (2002). Mental health first aid training for the public: Evaluation of effects on knowledge, attitudes and helping behavior. BMC Psychiatry, 2(1), 10. https://doi.org/10.1186/1471-244X-2-10

Kitchener, B. A., \& Jorm, A. F. (2004). Mental health first aid training in a workplace setting: A randomized controlled trial [ISRCTN13249129]. BMC Psychiatry, 4(1). https://doi.org/10.1186/1471-244X-4-23

Kitchener, B. A., \& Jorm, A. F. (2008). Mental health first aid: An international programme for early intervention. Early Intervention in Psychiatry, 2(1), 55-61. https://doi.org/10.1111/j.1751-7893.2007.00056.x

Klink, J. J. L. van der, Blonk, R. W. B., Schene, A. H., \& Dijk, F. J. H. van. (2001). The benefits of interventions for work-related stress. American Journal of Public Health, 91(2), 270-276. https://doi.org/10.2105/AJPH.91.2.270

Konovsky, M. A., \& Cropanzano, R. (1991). Perceived fairness of employee drug testing as a predictor of employee attitudes and job performance. Journal of Applied Psychology, 76(5), 698-707. http://dx.doi.org.proxy.lib.pdx.edu/10.1037/00219010.76 .5 .698 
Kraemer, T., \& Gouthier, M. H. J. (2014). How organizational pride and emotional exhaustion explain turnover intentions in call centers: A multi-group analysis with gender and organizational tenure. Journal of Service Management, 25(1), 125148. https://doi.org/10.1108/JOSM-07-2013-0173

Langer, E. J., \& Moldoveanu, M. (2000). The construct of mindfulness. Journal of Social Issues, 56(1), 1-9. https://doi.org/10.1111/0022-4537.00148

Langford, C. P. H., Bowsher, J., Maloney, J. P., \& Lillis, P. P. (1997). Social support: A conceptual analysis. Journal of Advanced Nursing, 25(1), 95-100. https://doi.org/10.1046/j.1365-2648.1997.1997025095.x

Leiter, M. P. (1991). Coping patterns as predictors of burnout: The function of control and escapist coping patterns. Journal of Organizational Behavior, 12(2), 123144. https://doi.org/10.1002/job.4030120205

Lieberman, M. A. (1986). Social supports: The consequences of psychologizing: A commentary. Journal of Consulting and Clinical Psychology, 54(4), 461-465. http://dx.doi.org/10.1037/0022-006X.54.4.461

Martin, A., Sanderson, K., \& Cocker, F. (2009). Meta-analysis of the effects of health promotion intervention in the workplace on depression and anxiety symptoms. Scandinavian Journal of Work, Environment \& Health; Stockholm, 35(1), 7-18.

Maslach, C., \& Jackson, S. E. (1986). Maslach Burnout Inventory manual (2nd ed.). Palo Alto, CA: Consulting Psychologists Press. 
Meyer, I. H. (2003). Prejudice, social stress, and mental health in lesbian, gay, and bisexual populations: Conceptual issues and research evidence. Psychological Bulletin, 129(5), 674-697. https://doi.org/10.1037/0033-2909.129.5.674

Miller, C. T., \& Major, B. (2000). Coping with stigma and prejudice. In T. F. Heatherton \& R. E. Kleck (Eds.), The Social Psychology of Stigma (pp. 243-272). New York: Guilford Press.

Montgomery, A. J., Panagopolou, E., de Wildt, M., \& Meenks, E. (2006). Work-family interference, emotional labor and burnout. Journal of Managerial Psychology, 21(1), 36-51. https://doi.org/10.1108/02683940610643206

Morris, J. A., \& Feldman, D. C. (1996). The dimensions, antecedents, and consequences of emotional labor. The Academy of Management Review, 21(4), 986-1010. https://doi.org/10.2307/259161

Murta, S. G., Sanderson, K., \& Oldenburg, B. (2007). Process evaluation in occupational stress management programs: A systematic review. American Journal of Health Promotion, 21(4), 248-254. https://doi.org/10.4278/0890-1171-21.4.248

Newport, F. (2018). In U.S., Estimate of LGBT Population Rises to 4.5\%. Retrieved March 19, 2019, from Gallup.com website: https://news.gallup.com/poll/234863/estimate-lgbt-population-rises.aspx 
Nielsen, K., \& Randall, R. (2009). Managers' active support when implementing teams: The impact on employee well-being. Applied Psychology: Health and Well-Being, 1(3), 374-390. https://doi.org/10.1111/j.1758-0854.2009.01016.x

Nielsen, K., Randall, R., Holten, A.-L., \& Gonzalez, E. R. (2010). Conducting organizational-level occupational health interventions: What works? Work \& Stress, 24(3), 234-259. https://doi.org/10.1080/02678373.2010.515393

Odle-Dusseau, H. N., Hammer, L. B., Crain, T. L., \& Bodner, T. E. (2016). The influence of family-supportive supervisor training on employee job performance and attitudes: An organizational work-family intervention. Journal of Occupational Health Psychology, 21(3), 296-308.

http://dx.doi.org.proxy.lib.pdx.edu/10.1037/a0039961

Okhuysen, G. A., \& Eisenhardt, K. M. (2002). Integrating knowledge in groups: How formal interventions enable flexibility. Organization Science, 13(4), 370-386. Retrieved from JSTOR.

Parker, S. K., Morgeson, F. P., \& Johns, G. (2017). One hundred years of work design research: Looking back and looking forward. Journal of Applied Psychology, 102(3), 403-420. http://dx.doi.org/10.1037/ap10000106

Rafaeli, A. (1989). When cashiers meet customers: An analysis of the role of supermarket cashiers. The Academy of Management Journal, 32(2), 245-273. https://doi.org/10.2307/256362 
Rauhala, A., Kivimäki, M., Fagerström, L., Elovainio, M., Virtanen, M., Vahtera, J., ... Kinnunen, J. (2007). What degree of work overload is likely to cause increased sickness absenteeism among nurses? Evidence from the RAFAELA patient classification system. Journal of Advanced Nursing, 57(3), 286-295. https://doi.org/10.1111/j.1365-2648.2006.04118.x

Rhoades, L., Eisenberger, R., \& Armeli, S. (2001). Affective commitment to the organization: The contribution of perceived organizational support. Journal of Applied Psychology, 86(5), 825-836.

http://dx.doi.org.proxy.lib.pdx.edu/10.1037/0021-9010.86.5.825

Richardson, K. M., \& Rothstein, H. R. (2008). Effects of occupational stress management intervention programs: A meta-analysis. Journal of Occupational Health Psychology, 13(1), 69-93. http://dx.doi.org.proxy.lib.pdx.edu/10.1037/10768998.13.1.69

Roth, S., \& Cohen, L. J. (1986). Approach, avoidance, and coping with stress. American Psychologist, 41(7), 813-819. http://dx.doi.org.proxy.lib.pdx.edu/10.1037/0003066X.41.7.813

Saks, A. M. (2002). So what is a good transfer of training estimate? A reply to Fitzpatrick. The Industrial-Organizational Psychologist, 39, 29-30.

Sauter, S. L., Murphy, L. R., \& Hurrell, J. J. (1992). Prevention of work-related psychological disorders: A national strategy proposed by the National Institute for Occupational Safety and Health (NIOSH). In G. P. Keita (Ed.), Work and well- 
being: An agenda for the 1990s. (pp. 17-40, Chapter viii, 228 Pages). Retrieved from

https://search.proquest.com/docview/614168493/abstract/B62894BADC5B4B60P $\mathrm{Q} / 1$

Savicki, V. (2002). Burnout across thirteen cultures: Stress and coping in child and youth care workers. Retrieved from https://search-proquestcom.proxy.lib.pdx.edu/docview/619740353/FAFD863A9ABB4BA2PQ/5

Schafer, J. L., \& Graham, J. W. (2002). Missing data: Our view of the state of the art. Psychological Methods, 7(2), 147-177. http://dx.doi.org.proxy.lib.pdx.edu/10.1037/1082-989X.7.2.147

Schaufeli, W. B., \& Bakker, A. B. (2004). Job demands, job resources, and their relationship with burnout and engagement: A multi-sample study. Journal of Organizational Behavior, 25(3), 293-315. https://doi.org/10.1002/job.248

Schreurs, B. H. J., Hetty van Emmerik, Ij., Günter, H., \& Germeys, F. (2012). A weekly diary study on the buffering role of social support in the relationship between job insecurity and employee performance. Human Resource Management, 51(2), 259-279. https://doi.org/10.1002/hrm.21465

Snijders, T. A. B., \& Bosker, R. J. (2012). Multilevel analysis: An introduction to basic and advanced multilevel modeling (2nd ed.). London: Sage Publishers. 
Suresh, K. (2011). An overview of randomization techniques: An unbiased assessment of outcome in clinical research. Journal of Human Reproductive Sciences, 4(1), 8. https://doi.org/10.4103/0974-1208.82352

Taylor, T. H. (2012). Ceiling Effect. In N. Salkind (Ed.), Encyclopedia of Research Design. https://doi.org/10.4135/9781412961288

Tett, R. P., \& Meyer, J. P. (1993). Job satisfaction, organizational commitment, turnover intention, and turnover: Path analyses based on meta-analytic findings. Personnel Psychology, 46(2), 259-293. https://doi.org/10.1111/j.1744-6570.1993.tb00874.x

Thoits, P. A. (1982). Conceptual, methodological, and theoretical problems in studying social support as a buffer against life stress. Journal of Health and Social Behavior, 23(2), 145-159. https://doi.org/10.2307/2136511

Thorndike, E. L. (1920). A constant error in psychological ratings. Journal of Applied Psychology, 4(1), 25-29. https://doi.org/10.1037/h0071663

U.S. Department of Labor, B. of L. S. (2018, February 14). Customer Service Representatives: Occupational Outlook Handbook: U.S. Bureau of Labor Statistics. Retrieved February 14, 2018, from U.S. Bureau of Labor Statistics website: https://www.bls.gov/ooh/office-and-administrative-support/customerservice-representatives.htm 
Viswesvaran, C., Sanchez, J. I., \& Fisher, J. (1999). The role of social support in the process of work stress: A meta-analysis. Journal of Vocational Behavior, 54(2), 314-334. https://doi.org/10.1006/jvbe.1998.1661

Wang, J., \& Johnson, D. E. (2019). An examination of discrepancies in multiple imputation procedures between SAS $®$ and SPSS $®$. The American Statistician, 73(1), 80-88. https://doi.org/10.1080/00031305.2018.1437078

Wharton, A. S., \& Erickson, R. J. (1993). Managing emotions on the job and at home: Understanding the consequences of multiple emotional roles. The Academy of Management Review, 18(3), 457-486. https://doi.org/10.2307/258905

Wright, P., Szeto, W. F., \& Geroy, G. D. (2007). The use of biodata for the recruitment of call center operators in the Asian leisure/gaming industry. International Journal of Hospitality \& Tourism Administration, 8(1), 61-76. https://doi.org/10.1300/J149v08n01_04 


\section{Appendices}

Appendix A: Assessment measures

\section{PERCEIVED SUPERVISOR SUPPORT}

Instructions: Listed below are statements that represent possible opinions that you may have about your manager. Please indicate the degree of your agreement or disagreement using the following scale.

1=Strongly disagree; $2=$ Disagree; $3=$ Somewhat disagree; $4=$ Somewhat agree 5=Agree; 6=Strongly agree

1. My manager values my contribution.

2. My manager fails to appreciate any extra effort from me. (R)

3. My manager would ignore any complaint from me. (R)

4. My manager really cares about my well-being.

5. Even if I did the best job possible, my manager would fail to notice. (R)

6. My manager cares about my general satisfaction at work.

7. My manager shows very little concern for me. (R)

8. My manager takes pride in my accomplishments at work.

BEHAVIOR CHECKLIST (Dimoff, 2013)

Instructions: Please use the scale below to rate the extent to which you agree with each statement.

$1=$ Strongly disagree; $2=$ Disagree $; 3=$ Somewhat disagree; $4=$ Somewhat agree $; 5=$ Agree; 6=Strongly agree

1. My supervisor recognizes when I am having a difficult time.

2. My supervisor addresses performance, behavior, or workplace issues.

3. My supervisor asks employees how they are doing on a regular basis.

4. My supervisor listens to employees when he/she asks them how they are doing.

5. My supervisor tells employees about resources that might help them.

6. My supervisor encourages employees to take care of their mental health.

7. My supervisor listens to employees when they have work-related concerns.

8. My supervisor intervenes when he/she notices that employees seem stressed out.

9. My supervisor talks to employees if they don't seem to be acting like themselves at work.

10. My supervisor talks about his/her own experiences related to mental health.

11. My supervisor talks to his/her employees about stress management techniques. 
EMOTIONAL LABOR (Brotheridge \& Lee, 1998)

Duration

A typical interaction I have with a customer takes about __ minutes.

Instructions: Using the scale below, please rate the extent to which you agree with the following statements.

$1=$ Strongly disagree; $2=$ Disagree; $3=$ Somewhat disagree; $4=$ Somewhat agree; $5=$ Agree; 6=Strongly agree

My job as a Receptionist requires me to...

Intensity

Express intense emotions.

Show some strong emotions.

Variety

Display many different kinds of emotions.

Express many different emotions.

Display many different emotions when interacting with others.

Surface Acting

Resist expressing my true feelings.

Pretend to have emotions that I don't really have.

Hide my true feelings about a situation.

Deep Acting

Make an effort to actually feel the emotions that I need to display to others.

Try to actually experience the emotions that I must show.

Really try to feel the emotions I have to show as part of my job.

BURNOUT (Maslach \& Jackson, 1986)

The following questions ask you to think about how you feel when you are at work. Using the scale below, please respond to each statement as accurately as possible by indicating how often you have experienced the following symptoms at work.

1=Never, 2=Very rarely, 3=Rarely, 4=Occasionally, 5=Frequently, $6=$ Very frequently

1. I feel emotionally drained from my work.

2. I feel used up at the end of each workday.

3. I feel tired when I get up in the morning and have to face another day on the job.

4. Working all day is a real strain for me.

5. I can effectively solve the problems that arise in my work.

6. I feel burned out from my work.

7. I feel I am making an effective contribution to what this organization does.

8. I have become less interested in my work since I started this job.

9. I have become less enthusiastic about my work. 
10. In my opinion, I am good at my job.

11. I feel exhilarated when I accomplish something at work.

12. I have accomplished many worthwhile things in my job.

13. I just want to do my job and not be bothered.

14. I have become more cynical about whether my work contributes to anything.

15. I doubt the significance of my work.

16. At my work I feel confident that I am effective at getting things done.

\section{COPING (Carver, 1997)}

Instructions: Please use the scale below to indicate what you generally do and feel, when you experience stressful events at work. Obviously, different events bring out somewhat different responses, but think about what you usually do when you are under a lot of stress.

$1=$ I usually don't do this at all; $2=$ I usually do this a little bit; $3=I$ usually do this a medium amount; 4=I usually do this a lot

1. I concentrate my efforts on doing something about the situation.

2. I take action to try to make the situation better.

3. I try to come up with a strategy about what to do.

4. I try thinking hard about what steps to take.

5. I try to see it in a different light, to make it seem more positive.

6. I look for something good about what is happening.

7. I accept the reality of the fact that it has happened

8. I learn to live with it.

9. I make jokes about it.

10. I make fun of the situation.

11. I try to find comfort in my religion or spiritual beliefs.

12. I pray or mediate.

13. I get emotional support from others.

14. I get comfort and understanding from someone.

15. I try to get advice or help from others about what to do.

16. I get help or advice from other people.

17. I turn to work or other activities to take my mind off things.

18. I do something to think about it less, such as going to movies, watching TV, reading, daydreaming, sleeping, or shopping.

19. I say to myself "this isn't real."

20. I refuse to believe that it has happened.

21 . I say things to let my unpleasant feelings escape.

22. I express my negative feelings.

23. I use alcohol or other drugs to make myself feel better.

24. I use alcohol or other drugs to help me get through it.

25. I give up trying to deal with it.

26 . I give up the attempt to cope.

27. I criticize myself.

28. I blame myself for things that happen. 
TURNOVER INTENTIONS (Konovsky \& Cropanzano, 1991)

Instructions: Using the scale below, please rate the extent to which you agree with each of the following statements.

1=Strongly disagree; $2=$ Disagree; $3=$ Somewhat disagree; $4=$ Somewhat agree $;$ 5=Agree; 6=Strongly agree

1. I often think about quitting my job.

2. I will probably look for a new job within the next year

3. It is very likely that I will leave this job within the next year.

\section{DEMOGRAPHICS}

Demographics

What is your sex?

Male Female

What is your age?

$\underline{\text { Tenure }}$

How long have you worked at \{company name $\}$ ?

What is your current position at \{company name $\}$ ?

How long have you been in this position at \{company name\}?

Where do you primarily work (e.g., Beaverton, Pearl, Headquarters)?

Work Environment

Approximately how frequently do you interact with your supervisor?

Every day Most Days Once a Week Bi-Weekly Once a Month Every 3 Months

\section{Experience with Mental Health}

Have you or a close friend or family member ever suffered from any type of mental illness?

\section{Yes}

No 
Appendix B: Weekly diary survey measures

Think about a time in the last week when you were struggling at work (e.g. wanted to leave work early, felt like crying at your desk, were frustrated on a call, etc.)

1. Did your supervisor notice you were struggling on their own?
a. Yes
b. No

2. What did your supervisor do to provide support?

a. He/She asked me how I was doing.

b. He/She listened to my concerns.

c. He/She suggested resources that might help me.

d. He/She encouraged me to take care of my mental health.

e. He/She talked about his/her own experiences related to struggling.

f. Other

3. What did you do?

a. I came up with a strategy about what to do

b. I took action to try to make the situation better

c. I got help or advice from other people

d. I expressed my negative emotions/feelings about the situation

e. I tried not to think about it

f. I gave up trying to fix the situation

g. Other

4. This week, how often did you feel like leaving work early or avoiding calls because you were struggling?

1=Never; 2=Very rarely; 3=Rarely; 4=Occasionally; 5=Frequently; 6=Very frequently

5. This week, I seriously considered looking for a new job.

$1=$ Strongly disagree; $2=$ Disagree; $3=$ Somewhat disagree; $4=$ Somewhat agree; 5=Agree; 6=Strongly agree

6. Please feel free to tell us more about your struggles this week. 